\title{
Economic Evaluation of Pharmaco- and Behavioral Therapies for Smoking Cessation: A Critical and Systematic Review of Empirical Research
}

\author{
Jennifer Prah Ruger and Christina M. Lazar \\ School of Public Health, School of Medicine, Yale University, New Haven, Connecticut, \\ 06520-8034
}

Jennifer Prah Ruger: jennifer.ruger@yale.edu; Christina M. Lazar: christina.lazar@yale.edu

\begin{abstract}
Economic evaluations are an important tool to improve our understanding of the costs and effects of health care services and to create sustainable health care systems. This article critically assesses empirical evidence from economic evaluations of pharmaco- and behavioral therapies for smoking cessation. A comprehensive literature review of PubMed and the British National Health Service Economic Evaluation Database was conducted. The search identified 15 articles on nicotine-based pharmacotherapies, 12 articles on nonnicotine based pharmacotherapies, no articles on selegiline, and 10 articles on brief counseling for smoking cessation treatment. Results show that both pharmaco- and behavioral therapies for smoking cessation are cost-effective or even cost-saving. The review highlights several shortcomings in methodology and a lack of standardization of current economic evaluations. Efforts to improve methodology will help make future studies more comparable and increase the evidence base so that such evaluations can be more useful to public health practitioners and policy makers.
\end{abstract}

\section{Keywords}

economic evaluation; cost-effectiveness; cost-saving; pharmacotherapy; behavioral therapy; smoking cessation

\section{INTRODUCTION}

Cigarette smoking is the leading cause of avoidable morbidity and premature mortality in the United States. Each year there are nearly five million smoking-attributable deaths worldwide (68) and $\sim 443,000$ smoking-attributable deaths and 5.1 million years of potential life lost (YPLL) in just the United States (20). Approximately 8.6 million people in the United States suffer from 12.7 million cases of smoking-attributable conditions, including chronic bronchitis, emphysema, and heart attacks (19). The economic costs of smoking to individuals and society are significant and increasing; worldwide, health care costs attributed to tobacco range from $\$ 2.25$ billion in the United Kingdom to $\$ 3.5$ billion in China, $\$ 6$ billion in Australia, and \$14.7 billion in Germany (82). Each year in the United States alone, smoking incurs $\sim \$ 157$ billion in economic losses related to health: $\$ 75$ billion

Copyright $@ 2012$ by Annual Reviews. All rights reserved DISCLOSURE STATEMENT

The authors are not aware of any affiliations, memberships, funding, or financial holdings that might be perceived as affecting the objectivity of this review. 
in direct medical costs and $\$ 82$ billion in lost productivity $(18,19)$. From both health and economic perspectives, smoking is a major public health problem (33).

Many interventions exist to aid smokers in cessation attempts (Table 1). Smoking cessation therapies can be classified as pharmacotherapies or behavioral therapies. Pharmacotherapies include both nicotine-based and nonnicotine-based medications. The U.S. Food and Drug Administration (FDA) has approved five nicotine-replacement therapies (NRT) (patch, gum, inhaler, lozenge, and nasal spray) and two nonnicotine-based agents (bupropion and varenicline). Additionally, second-line pharmacotherapies such as clonidine $(37,44)$ and nortriptyline (41) are often prescribed for patients who are unable to use first-line medications or when first-line medications are unhelpful. Other pharmacotherapies, although not FDA-approved for smoking cessation, include fluoxetine, sertraline, paroxetine, naltrexone, selegiline, rimonabant, doxepin (28), and moclobemide (8). Behavioral therapies include partner support, self-help interventions, and counseling services such as telephone counseling (proactive and reactive), professional advice from a nurse or physician, and intensive counseling (individual and group).

Smoking cessation therapies vary in scope, intensity, and effectiveness. Although pharmacotherapies have higher material costs compared with behavioral treatments, they tend to require fewer human resources to administer and can thus be as, if not more, costeffective for smoking cessation. One meta-analysis of placebo-controlled randomized trials compared the efficacy of NRT, bupropion, and varenicline (29). The study found that all seven of the tested pharmacotherapies were more efficacious at promoting smoking abstinence compared with placebo. In addition, findings suggested that varenicline is more efficacious than bupropion. Another systematic review examined the effectiveness of drug and behavioral therapies on smoking cessation in adults (61). Study results were consistent with previous reviews, finding that, individually and combined, counseling and pharmacotherapy interventions were effective at decreasing smoking rates but that self-help methods alone were relatively ineffective.

Smoking cessation therapies have the potential to be cost-effective and even cost-saving for society. Economic evaluations of smoking cessation therapies provide useful data about the costs and benefits of various smoking cessation interventions relative to each other as well as relative to other health interventions. Because resources are limited, effectiveness and cost-effectiveness must be considered. Cost-effectiveness (CEA) and cost-utility (CUA) analyses, in particular, are useful tools to compare the costs per unit of health outcome (e.g., life years, quality-adjusted life years) between interventions and can help determine value for money and whether a program is worth implementing (39). Cost-benefit analysis (CBA) translates benefits into monetary units for cost-benefit ratios (e.g., 3:1) (see Table 2 for types of economic evaluations). Although cost-effectiveness is just one of many factors that affect policy decisions, economic evaluations are important for policy decision-making and for identifying sustainable services. Economic evaluations are needed to determine optimal resource allocation and to identify efficient programs that support a sustainable health care system.

Evidence-based public health, like evidence-based medicine, requires public health researchers and practitioners to consider scientific evidence when developing policies and when choosing and assessing programs. However, whereas medical studies typically collect evidence from what has been considered the gold standard in medical research studies (i.e., randomized-controlled trials), it is more feasible for public health studies conducted at the population level to utilize alternative research methods (e.g., quasi-experimental studies, cross-sectional studies, natural experiments). These studies often lack a good control group and require considerable time and resources to implement (15). In addition, the literature 
shows a limited number of evidence-based studies on preventive and cost-effective public health interventions; in a systematic review of the evidence base, one study looking at modifiable risk factors of conditions constituting a major public health burden found that only a small percentage of public health interventions have cost-effectiveness and preventable fraction (a measure of the proportion of a health problem that can be avoided when an intervention is carried out) data available $(15,74)$. Increasing the availability and subsequent adoption of evidence-based programs and policies with demonstrated effectiveness and cost-effectiveness will likely improve health outcomes and lead to a greater return on investment (15). Several types of evidence can be used to inform programs and policies: "Type 1 evidence defines the causes of diseases and the magnitude, severity, and preventability of risk factors and diseases... Type 2 evidence describes the relative impact of specific interventions that do or do not improve health... Type 3 evidence (of which we have the least) shows how and under which contextual conditions interventions were implemented and how they were received" $(15$, p. 179).

Studies on tobacco use have collected data that represents each of these evidence types: Smoking has been identified as a public health threat (type 1 evidence), specific pharmacoand behavioral therapies have been effective in aiding smoking cessation attempts (type 2 evidence), and economic evaluations have measured the adaptability and sustainability of such interventions in specific settings and populations (type 3 evidence). Systematic reviews hold promise in their ability to summarize the evidence base methodically to aid public health policy makers. A meaningful review, however, must take care to employ rigorous methods and carefully evaluate the validity of study outcomes to provide useful information about the effectiveness and cost-effectiveness of public health interventions (54). This review expands the evidence base by analyzing economic evaluations of smoking cessation therapies in a systematic way. It complements previously published Annual Review of Public Health reviews on CEAs $(6,39)$, summaries of the evidence base $(15,54)$, and smoking cessation research (69) (see Related Resources, below, for other Annual Review articles on smoking cessation).

The purpose of this article is to systematically review and critically assess the existing economic evaluations of pharmaco- and behavioral therapies for smoking cessation. We summarize and assess the available cost and outcomes data for smoking cessation interventions for patients, hospitals, and society and discuss the greater clinical and public health implications of our findings. This article aims to provide public health practitioners, clinicians, and policy makers with a greater evidence base and a better understanding of economic evaluations for smoking cessation interventions that will help guide policy decisions and future research and clinical practice.

\section{METHODS}

\section{Search Strategy and Selection Criteria}

We conducted a comprehensive literature search employing rigorous search strategies for identifying and selecting studies, as described elsewhere (17, 26, 50, 53, 58, 63, 64, 66, 73). Inclusion criteria were economic evaluations of nicotine- and nonnicotine-based pharmacotherapies, selegiline, and brief counseling therapies for smoking cessation. We searched PubMed and the British National Health Service Economic Evaluation Database for English-language articles using the search terms "economic" or "cost" or "cost effectiveness" or "cost utility" or "cost benefit" or "price" and "smoking" or "tobacco" or "cigarette" or "smoking cessation" combined with the search terms "nicotine gum" or "nicotine patch" or "nicotine nasal spray" or "nicotine inhaler" or "sublingual tablet" or "sublingual lozenge" or "nicotine replacement therapy" or "NRT" for economic evaluations of nicotine-based pharmacotherapies, or "bupropion" or "zyban" or "wellbutrin" or 
"varenicline" or "chantix" or "doxepin" or "nortriptyline" or "clonidine" or "moclobemide" or "nortriptyline" or "fluoxetine" or "sertraline" or "paroxetine" or "rimonabant" for economic evaluations of nonnicotine-based pharmacotherapies, or "selegiline" for economic evaluations of selegiline, or "brief counseling" or "brief advice" or "brief behavioral" or "brief psychological" for economic evaluations of brief counseling therapies.

The initial search identified 84 articles on nicotine-based pharmacotherapies, 45 articles on nonnicotine-based pharmacotherapies, 14 articles on selegiline, and 31 articles on brief counseling. Two reviewers inspected study abstracts and included articles that met the following predetermined criteria: $(a)$ study is directed at the question identified; $(b)$ study undertakes original economic analysis (reviews were excluded); and (c) study uses an appropriate outcome measurement [health outcomes such as quality-adjusted life years (QALYs), quit or abstinence rates, life expectancy]. Methodological quality was assessed using standard inclusion criteria for economic evaluation endorsed by the Task Force on Community Preventive Services in the Guide to Community Preventive Services (17). Under these criteria, studies must use one of four analytical methods recommended by Drummond and colleagues (27) (see Table 2).

Of the 84 articles on nicotine-based pharmacotherapies identified, 69 were excluded because they did not meet inclusion criteria. This left 15 economic evaluations in our analysis. Of the 45 articles on nonnicotine-based pharmacotherapies, 33 articles did not meet inclusion criteria. This left 12 economic evaluations in our analysis. Of the 14 articles on selegiline, all were excluded because they did not focus on selegiline for smoking cessation, leaving no articles in the final analysis. Finally, of the 31 articles on brief counseling, 21 articles did not meet inclusion criteria. This left 10 articles in our analysis. Figure 1 summarizes our approach.

\section{Data Extraction and Analysis}

Full copies of the final 37 economic evaluations were obtained and data were extracted by two people (one person initially and another person fact-checked these extractions) and analyzed by another with training in decision analysis and cost, cost benefit, costeffectiveness, and cost-utility analyses. Data extracted included type of economic evaluation, study design, main outcome measures, cost components, and study results (see Table 3).

Quality assessment of included economic evaluations was based on the checklist for reporting reference-case CUA recommended by the Panel on Cost-Effectiveness in Health and Medicine (38), the data auditing form developed by researchers at the Harvard Center for Risk Analysis (http://www.hcra.harvard.edu), and the guidelines for economic submission to the British Medical Journal (BMJ) (26). Differences in methodology and intervention type made it impossible to combine study results to generate summary cost or cost-effectiveness measures of smoking cessation interventions. Because the studies we analyzed were heterogeneous, we conducted a narrative synthesis (78) instead of a formal meta-analysis. A narrative synthesis, unlike a meta-analysis, undertakes no quantitative synthesis, but rather summarizes the type, statistical significance, and distribution of a program's costs and effectiveness.

\section{RESULTS}

Below we present the results of our narrative synthesis. Results from all studies reporting outcomes in other currencies were converted into U.S. dollars. 


\section{Economic Evaluations of Nicotine-Replacement Therapy for Smoking Cessation}

Fifteen studies meeting the inclusion criteria conducted economic evaluations of NRT for smoking cessation (Table 4). Economic evaluations of NRT focus on a number of different treatments and programs ranging from the addition of NRT in quitline programs to NRT being added to brief counseling sessions. Study designs included randomized-controlled trials, observational studies, and analytic models. Perspectives varied from that of the program, to national health care systems, payer, and society. Outcome measures differed between studies: 4 studies measured QALYs saved or gained, 10 studies measured life years saved or gained, 6 studies measured quit rates, and 3 studies measured abstinence rates (some studies reported more than one outcome measure).

Three studies conducted a CEA using a randomized-controlled trial study design. Randomized-controlled trials are the gold standard of clinical evidence. Conducting economic evaluations alongside controlled trials enhances the reliability and validity of data on intervention costs because all consumed inputs are measured and valued. One study measuring the cost-effectiveness of brief counseling in primary care settings with and without a nicotine patch prescription from the perspective of the British National Health Service (NHS) found an incremental cost per life year saved ranging from \$568 to \$1,294 with the addition of NRT (72). Another study compared the cost-effectiveness of general practitioner training plus physician incentive for each successful quit, training plus NRT or bupropion, and the combination of those two strategies. Compared with usual care, general practitioner training plus medications and training plus both medication and remuneration were cost-effective. The cost per additional quitter ranged from $\$ 97$ per patient enrolled for training plus both NRT and remuneration program to \$107 per patient enrolled for training plus medication (67). A third study investigated the cost-effectiveness of brief, moderate, and intensive telephone counseling with and without NRT. Compared with brief counseling with no NRT, the added costs for each additional quit was $\$ 2,467$ for brief counseling plus NRT, \$1,912 for moderate counseling alone, \$2,109 for moderate counseling plus NRT, $\$ 2,640$ for intensive counseling alone, and $\$ 2,112$ for intensive counseling plus NRT (45).

Two evaluations examined the cost-effectiveness of quitline programs before and after the addition of free nicotine patches. One CEA compared quit rates and life years saved of Oregon quitline callers before and after a free patch initiative (31). Cost components included intervention and media promotion costs. Compared with the preinitiative program, the free patch initiative quadrupled the number of quitters and lowered total costs per quit by $\$ 2,688$ ( $\$ 3,738$ preinitiative versus $\$ 1,050$ postinitiative), with an incremental costeffectiveness of $\$ 86$ per life year saved and $\$ 174$ per additional quit. A similar study measured the direct costs of adding the nicotine patch or gum to a program for quitline callers enrolled in multisession counseling in Minnesota (2). Results showed that the monthly average number of exsmokers rose from 15.5 preinitiative to 123.6 postinitiative with a cost per quit increase from $\$ 1,362$ to $\$ 1,934$ (not statistically significant).

Three studies used a decision analytic model to determine cost-effectiveness of different smoking cessation treatments. One study compared physician-based smoking cessation counseling to counseling plus the nicotine patch (32). The patch yielded one additional lifetime quitter at a cost of $\$ 7,332$, with an incremental cost-effectiveness that ranged by age from $\$ 4,390$ to $\$ 10,943$ per QALY in men and from $\$ 4,955$ to $\$ 6,983$ per QALY in women. A second study determined the cost-effectiveness of five counseling interventions with and without transdermal nicotine and nicotine gum recommended in The Agency for Health Care Policy and Research Guideline for Smoking Cessation (23). After one year, recommended guidelines would cost an average of \$1,915 per QALY saved, \$2,587 per life year saved, and $\$ 3,779$ per quitter. The study found the cost per QALY saved ranged from $\$ 1,108$ to $\$ 4,542$ and that the more intensive the intervention, the lower the cost per QALY. 
In another study, investigators compared the cost-effectiveness of brief advice and more intensive counseling with and without NRT and bupropion (71) (Table 5). Costs per life years saved were lower for more intensive counseling; incremental cost per life years saved ranged from $\$ 1,441$ (intensive) to $\$ 3,455$ (brief advice) for NRT, $\$ 920$ (intensive) to $\$ 2,150$ (brief advice) for bupropion SR, and $\$ 1,282$ (intensive) to $\$ 2,836$ (brief advice) for NRT and bupropion SR together.

Five studies investigated the cost-effectiveness of adding NRT to counseling by modeling smoking populations. In a CEA of the nicotine patch as a supplement to brief physician advisement during routine office visits, one study found incremental costs per year of life saved ranged from $\$ 1,796$ to $\$ 2,949$ for men and from $\$ 3,040$ to $\$ 4,391$ for women (80). Another study looked at programs adding NRT to brief counseling in primary care and found that cost-effectiveness varied significantly between six western countries (21). Published data and market values from each country were used to estimate the cost of drugs and physician services. The incremental costs per life year saved ranged from $\$ 2,230$ in Spain for men to $\$ 7,643$ in the United States for women using nicotine gum; $\$ 3,480$ in Switzerland for men to $\$ 8,700$ in France for women using the nicotine inhaler; $\$ 1,758$ in Spain for men to $\$ 5,131$ in the United Kingdom for women using the nicotine patch; $\$ 1,935$ in Spain for men to $\$ 7,969$ in the United States for women using nicotine spray; and $\$ 792$ in Canada for men to $\$ 2,922$ in the United States for women using bupropion. A study in the Seychelles examining the incremental cost-effectiveness of five first-line pharmacological smoking cessation therapies and physician counseling found the incremental cost per life year saved using U.S. treatment prices to be $\$ 4,291$ for the nicotine inhaler, $\$ 3,712$ for nicotine gum, $\$ 1,982$ for the nicotine patch, and $\$ 1,324$ for bupropion (36). In an earlier analysis, another study measured the cost-effectiveness of adding nicotine gum to physician advice and counseling in a primary care setting (59). The cost per year of life saved ranged from $\$ 4,113$ to $\$ 6,465$ for men and $\$ 6,880$ to $\$ 9,473$ for women. A study in the Netherlands compared five smoking cessation interventions: telephone counseling, minimal counseling with and without NRT, and intensive counseling with NRT or bupropion (30). Cost per QALY gained over a 75-year period ranged from $\$ 1,109$ for telephone counseling to $\$ 4,939$ for intensive counseling with nicotine patches or gum.

Two studies investigated the cost-effectiveness of pharmacist-directed smoking cessation programs. A cohort study in Northern Ireland compared the pharmacists action on smoking (PAS) model, a community pharmacy-based smoking cessation program, to a matched cohort receiving usual care (22). The study found cost per life year saved in the PAS program ranged from $\$ 337$ to $\$ 603$ for men and from $\$ 310$ to $\$ 1,322$ for women. Modeling the cost-effectiveness of a community pharmacy-based smoking cessation program, another study found an incremental cost per quit using the pharmacist-directed program, as compared with self-directed quit attempts, of $\$ 1,232$ for nicotine gum, $\$ 1,150$ for bupropion, $\$ 936$ for the nicotine patch, and $\$ 236$ for the cold turkey method (76).

\section{Economic Evaluations of Nonnicotine-Based Pharmacotherapies for Smoking Cessation}

Twelve studies meeting the inclusion criteria conducted economic evaluations of nonnicotine-based pharmacotherapies for smoking cessation (Table 5). Of these, four were CUAs, three were CEAs, four were CEA and CUA, and one was a CBA. Nine studies used a simulated model, and three studies used a decision-analytic model. Analysis perspectives varied among studies, ranging from societal to payers or health care systems. Eight studies reported results in QALYs saved or gained, four studies reported results in life years saved or gained, three studies reported results as quit rates, and one study reported results as abstinence rates (some studies reported more than one outcome measure). 
Four economic evaluations used the benefits of smoking cessation on outcomes (BENESCO) Markov model to compare varenicline with other smoking cessation interventions. Cost analysis in all four studies included intervention costs and direct medical costs of smoking-related diseases: stroke, chronic obstructive pulmonary disease, lung cancer, and coronary heart disease. Sometimes asthma exacerbation was included in analysis. In a hypothetical cohort of Dutch smokers making a one-time quit attempt, one study compared the cost-effectiveness of treatment with varenicline to treatment with bupropion, nortriptyline, NRT, or no treatment (46). Lifetime costs were assessed from the perspective of the Dutch health care system. The study found that varenicline costs $\$ 1,472$ per QALY gained compared with nortriptyline, and \$285 per QALY gained compared with unaided cessation. The cost of varenicline per additional quitter ranged from $\$ 919$ to $\$ 3,809$ compared with NRT and nortriptyline, respectively. A second study compared the costeffectiveness of varenicline, bupropion, and NRT with and without brief counseling to unaided cessation in a cohort of Belgian smokers (3). Costs were assessed from a health care payer perspective. Varenicline dominated bupropion and NRT and was cost-effective compared with brief counseling alone and unaided cessation with a cost per QALY that ranged from $\$ 337$ to $\$ 2,325$, respectively. Another BENESCO model of a simulated cohort of smokers in Belgium, France, Sweden, and the United Kingdom compared the costeffectiveness of varenicline to NRT (11). This study found that using varenicline instead of NRT in a typical smoking cessation intervention was cost-saving in all countries except France, with a cost-effectiveness ratio of $\$ 3,936$ per QALY gained. A fourth study conducted a CUA of varenicline, bupropion, NRT, and unaided cessation in a hypothetical cohort of U.S. smokers (47). Costs were assessed from the perspective of the U.S. health care system. Varenicline dominated bupropion, NRT, and unaided cessation at 20 years and lifetime, as it was less costly and more effective than any other option.

Two studies used the BENESCO Markov model to assess costs of an additional 12 weeks of varenicline treatment for abstainers who completed a previous 12-week treatment. One CEA updated the BENESCO model to compare the 12 week course of varenicline to the usual 12week course of varenicline, bupropion, NRT, and unaided cessation in a hypothetical population of Americans. Over all subjects' lifetimes, the additional 12 weeks of varenicline treatment dominated all other strategies with the exception of the original 12-week course of varenicline and had an incremental cost of $\$ 972$ per QALY gained (51). A CUA used the BENESCO model to compare an additional 12-week course of varenicline therapy to placebo in a simulated cohort of Swedish smokers who had achieved abstinence following an initial 12-week treatment of varenicline (10). The study included intervention costs, smoking-related health care costs, and indirect (consumption, production) costs. Results found that, excluding indirect effects, an additional 12 weeks of varenicline therapy resulted in an incremental cost per QALY gained of $\$ 7,420$ in men and $\$ 7,464$ in women over a 50year timeframe. Including indirect effects, the incremental costs per QALY gained were $\$ 25,359$ for men and $\$ 25,660$ for women.

Three studies compared nonnicotine-based drugs to NRT or to counseling using statistical modeling. One study used an adaptation of the health and economic consequences of smoking (HECOS) interactive model to compare the cost-effectiveness of bupropion with NRT for smokers in Spain (4). This study was conducted from the national health system perspective and included intervention and tobacco-related health care costs. The study found that, at 20 years, bupropion and the nicotine patch produced a net savings of $\$ 32,920$ and $\$ 15,993$ per death prevented and a net savings of $\$ 3,852$ and $\$ 1,867$ per life year saved, respectively. A CUA used the global health outcomes simulation model to compare bupropion to the nicotine patch and nicotine gum in a model cohort of Swedish smokers (9). The study found that bupropion was cost-saving compared with both NRTs when direct and indirect effects were included. Incremental cost per QALY gained for bupropion was $\$ 702$ 
for men and $\$ 521$ for women compared with the nicotine patch when indirect costs were excluded. Another CUA used a Markov model to assess costs per QALY gained over the lifetime from adding varenicline therapy to smoking cessation counseling (48).The study found that adding varenicline to counseling increased QALYs and saved medical costs in men and had an incremental cost-effectiveness ratio of $\$ 3,010$ in women.

Three studies used a decision-analytic model to assess costs from various perspectives. The first study compared the economic effects of varenicline to nicotine patch, bupropion, and no intervention from the perspective of private health plans, state Medicaid, and employers in the United States (42). Compared with unaided cessation, the cost-effectiveness of varenicline per additional cessation at 2 years ranged from $\$ 648$ in the private health plan model to $\$ 836$ in the Medicaid model. In another CBA, a decision tree model was used to compare the costs of varenicline to bupropion from an employer perspective (49). At 1 year, employers saved $\$ 82$ for placebo, $\$ 151$ for bupropion (brand), \$270 for bupropion (generic), and $\$ 541$ per nonsmoking employee for varenicline. A third study used a decision-analytic model to estimate the cost per life years saved of advice or counseling alone and advice or counseling plus bupropion and/or NRT(71). Costs were calculated from the U.K. National Health Services perspective. The incremental cost per life year saved, compared with advice or counseling alone, was $\$ 1,441-\$ 3,455$ for NRT, $\$ 920-\$ 2,150$ for bupropion, and $\$ 1,282$ $\$ 2,836$ for NRT and bupropion together.

\section{Economic Evaluations of Selegiline for Smoking Cessation}

Our search did not identify any studies using selegiline for smoking cessation. We found that virtually all the articles identified in the initial term search were focused on the use of selegiline in the treatment of Parkinson disease and other neurological disorders $(16,43)$.

\section{Economic Evaluations of Brief Counseling for Smoking Cessation}

Ten studies meeting the inclusion criteria conducted economic evaluations of brief counseling therapies for smoking cessation (Table 6). Seven studies conducted CEAs, one study conducted a CUA, and two studies conducted both a CEA and CUA. Studies ranged in design and included randomized-controlled trials, cohort studies, and model estimates. Three studies measured main outcomes in QALYs, 6 studies measured main outcomes in quit rates, 6 studies measured main outcomes in life years saved or gained, 1 study measured main outcomes in abstinence rates, and 1 study measured the acceptability of a computerized intervention (some studies reported more than one outcome measure). Study perspectives of costs varied from societal to health care system to payer.

Four economic evaluations used a randomized trial study design; collecting cost data alongside controlled trials allows for careful delineation of intervention inputs and thus such studies have enhanced reliability and validity of data on intervention costs. One study compared the cost-effectiveness of motivational interviewing to brief advice for smoking cessation and relapse prevention in low-income pregnant women in Boston (65). ${ }^{1}$ For smoking cessation, motivational interviewing was more costly and less effective than brief advice. For relapse prevention, motivational interviewing cost $\$ 851$ per life year saved and \$628 per QALY saved. Another study analyzed the cost-effectiveness of a bedside counseling session versus usual care in patients from two acute care hospitals in the United States (52). The intervention consisted of a 20-min counseling session, video and self-help materials, and follow-up phone calls. The intervention cost $\$ 159$ per smoker, with an incremental cost per incremental quit of $\$ 3,697$. Incremental cost per incremental discounted

\footnotetext{
${ }^{1}$ An extensive review of economic evaluations of smoking cessation and relapse prevention programs among pregnant women can be found elsewhere (62).
} 
life year saved ranged from $\$ 1,691$ to $\$ 7,444$. Another randomized trial compared the costs of brief contact with a stepped smoking cessation program in mental health outpatients diagnosed with depression (7). Costs were evaluated from the health care payer perspective and included the cost of all smoking cessation services used as well as mental health care costs. Assuming smoking cessation adds 1.2 years of additional life, smoking cessation and mental health services together cost $\$ 9,580$ per life year gained and smoking cessation services cost $\$ 5,170$ per life year gained. A third study compared the cost-effectiveness of a self-help manual to assisted self-help with counselor (1). The study accounted for partner support. From a societal perspective, assisted self-help cost $\$ 56$ per participant, compared with the $\$ 20$ for manual-only intervention. Incremental cost per quit was \$691 and \$264 for manual-only intervention and $\$ 1,131$ and $\$ 973$ for assisted self-help intervention from societal and provider perspectives, respectively.

Two economic evaluations used an observational study design. One observational study in Scotland compared the cost-effectiveness of one-to-one counseling in pharmacies to group counseling in the community (12). Costs components included nicotine-replacement therapy, professional time, overhead costs, and cost of intervention materials. Results showed an incremental cost per four-week quitter to be $\$ 1,512$ for one-to-one support and $\$ 2,158$ for group support compared with self-quit attempts. Assuming permanent cessation leads to an average of 1.98 QALYs gained, the incremental cost per QALY is $\$ 8,620$ for one-to-one support and $\$ 10,579$ for community support. A cohort study assessed the costeffectiveness of a brief computerized smoking cessation intervention program for all smokers attending a non-cardiac surgical preadmission clinic in Australia (40). Economic assessment included the cost to create the computer programs and the cost of computer hardware and software used. At two months, the study found a cost per smoker of $\$ 146$ and a cost per quitter of $\$ 1,630$. Results extrapolated to one year showed a cost of $\$ 5.80$ per patient, \$24.19 per smoker, and \$271.47 per quitter.

Two studies used a Markov model to estimate cost-effectiveness of smoking cessation interventions. One study used a simulated cohort of Thai smokers to compare a structured community pharmacist-based smoking cessation program to usual care (75). Costs were assessed from the health care system perspective and included program costs and costs of smoking-attributable conditions. The program resulted in 0.18 and 0.24 life years gained and a cost savings to the health system of $\$ 500$ and $\$ 614$ for men and women, respectively. A second study used a Markov transition model to compare the American Lung Association's Not On Tobacco (N-O-T) teen smoking cessation program to a 20-min brief intervention in 17-25-year-old students in select Florida schools (25). The model predicted that, out of 100 students 10 participants in the N-O-T program would quit smoking and 14 would reduce smoking, resulting in 20.11 discounted life years saved. The incremental cost-effectiveness ratio for the N-O-T program was $\$ 443$ ( $\$ 274-\$ 1,029$ best- to worst-case scenarios) per discounted life year saved.

Two studies estimated costs for brief counseling sessions. One study compared the costeffectiveness of one-time counseling to annual counseling (70). Costs were assessed from a societal perspective and included intervention costs and cost of smoking-attributable illnesses. Excluding savings from prevented illness, the study found a cost-effectiveness of $\$ 1,100$ and $\$ 2,266$ per QALY saved for brief, one-time counseling and annual counseling. When costs for smoking-attributable illnesses were factored in, both one-time and annual counseling programs were cost-saving with a net cost saved of $\$ 65$ and $\$ 542$ per smoker counseled, respectively. A second study analyzed the cost-effectiveness of brief counseling during a routine doctor's office visit in a hypothetical population (24). This study found that brief advice during routine office visits cost $\$ 705-\$ 988$ per year of life saved for men and $\$ 1,204-\$ 2,058$ per year of life saved for women. 


\section{DISCUSSION}

This review examines a wide variety of economic evaluations on pharmaco- and behavioral smoking cessation interventions. Results demonstrate that economic evaluations differ greatly in approach and evaluation methods used (e.g., different study designs, different outcome measures, different cost components) when reporting economic findings of smoking cessation therapies. Differences in data definition and estimation, discount rates, model assumptions, and perspectives affect study findings and limit our ability methodologically to draw direct conclusions about the effectiveness and cost-effectiveness of the different interventions in relation to each other. This diversity also makes it difficult to determine which of the different program characteristics (e.g., targeted populations and intervention types) leads one program to appear more cost-effective than others. For example, two studies compared the cost-effectiveness of quitline programs before and after the addition of free nicotine patches $(2,31)$. After the free patch initiative, both studies found an increase in the number of quitters; however, the Oregon study showed a substantial decrease in cost per quitter (31), whereas the Minnesota study showed a (statistically insignificant) increase in cost per quitter (2). Comparing cost inputs of the studies side by side, it appears that this difference arises because the Oregon study included media promotion costs in their analysis and the Minnesota study did not. Including media costs substantially increased the total program costs and cost per quit preinitiative. High program costs postinitiative were offset by the larger number of quitters, rendering the postinitiative to appear more cost-effective with a lower cost per quit compared with preinitiative. The Minnesota study did not include media promotion costs so the cost of NRT was the primary factor affecting total costs.

Although many of the economic studies in this review provide useful information about the value of the programs they assess, there are some substantive and methodological limitations of these studies. First, whereas several studies followed recommendations by the Panel on Cost-Effectiveness in Health and Medicine and used a randomized-controlled-trial study design $(1,7,45,52,65,67,72)$, many studies did not. Randomized-controlled trials, considered the gold standard of clinical evidence, help enhance the reliability and validity of data on intervention costs and effectiveness and are thus preferred; alternative study designs significantly limit the ability to reduce the bias and confounding inherent in nonrandomized study designs. Second, many studies did not use standardized cost measures, which limits the reliability and validity of cost estimates and our ability to compare intervention costs among studies. For example, some studies included only intervention costs, whereas others included direct and indirect medical costs as well as marketing costs associated with the intervention. In addition, many of these studies did not include cost data that had been discounted and comprehensively delineated. Rather, costs were typically estimated on the basis of a number of assumptions and guesstimates and may not accurately represent true costs. Thus, the true effects of smoking cessation on long-term medical spending have, in general, not been exhaustively examined. Third, not all studies conducted incremental CEAs or CUAs as recommended by the panel. Rather, many studies reported average costeffectiveness ratios for study interventions, limiting our ability to draw conclusions about the incremental or marginal differences in costs and outcomes of different interventions as compared with each other. Because few studies used comparable outcome measures (e.g., life years saved, QALY), it is not possible to assess whether such interventions achieve incremental health gains (at the margin) and to examine the incremental effectiveness of those improvements. Fourth, in terms of study perspective, the viewpoint for analysis has typically been that of the payer rather than that of society. In European studies, the viewpoint is typically the National Health Services or society. This broader viewpoint helps public health practitioners and policy makers understand the broader economic implications of smoking cessation programs. 
Lack of standardization in economic evaluation makes it difficult to compare across the studies that currently exist. In 1996, the U.S. Panel on Cost-Effectiveness in Health and Medicine published recommendations and guidelines to improve comparability of CEAs. Their guidelines recommend that $(a)$ all costs are measured from the societal perspective, $(b)$ cost estimates are converted to a common year, $(c)$ a rate of $3 \%$ is used to discount future outcomes and costs to present value, $(d)$ QALYs are used as the outcome metric, and (e) sensitivity analyses are performed $(6,38)$. Since publication of the panel's recommendations, there has been some improvement in the methods used over time $(13,14$, $56,57,58)$; however, this review and others $(13,35,63,64)$ indicate that economic evaluations are still not always adopting the panel's recommendations. The persistence of methodological problems in economic evaluations suggests there remains room for improvement.

Economic evaluations of smoking cessation therapies provide valuable (type 3 ) evidence on the context of public health interventions and provide researchers and policy makers with the information required to implement a program successfully in a particular setting. Type 3 evidence includes contextual information from five domains: population characteristics (e.g., race, socioeconomic status), interpersonal variables (e.g., family history of substance abuse), organizational variables (e.g., organizational capacity), social and cultural norms (e.g., acceptability of smoking), and political and economic factors (e.g., type of health care system) (15). This review highlights the contextual variables of smoking cessation therapies and compares programs implemented in varying contexts. We find that the costeffectiveness of smoking cessation therapies varies significantly by study population. One study comparing pharmacotherapies across six western countries found that substantial differences in physician payments contributed to much of the cost differences between countries (21). Another study conducted in the Seychelles identified pharmacotherapy prices as a substantial factor in cost analysis, particularly in developing countries where prices may be dependent on local production, licensing, infrastructure capacity, technology requirements, and capital investment (36). In addition, studies show considerable ranges in cost-effectiveness among interventions in groups of men versus women (80) and among people in different age groups; a higher cost per QALY is associated with interventions in older individuals (32).

Despite this variability in cost-effectiveness, smoking cessation interventions have compared favorably with other health care interventions. Because of their favorable return on investment, smoking cessation programs are regarded as the gold standard of costeffectiveness in health care (77). For example, in a study comparing interventions to prevent cardiovascular disease, smoking cessation was found to be the most cost-effective, above aspirin, antihypertensives, and statins (34). Yet, despite the need for efficient resource allocation and sustainable health care services, research shows that clinicians rarely subscribe to smoking cessation practices that are considered cost-effective. For example, clinical guidelines for treating tobacco use and dependence were developed by the U.S. Department of Health and Human Services to identify "effective, experimentally validated tobacco dependence clinical treatments and practices" (77, p. 3). The guidelines recommend clinicians use the five A's for treating tobacco use and dependence: "[A]sk about tobacco use; advise to quit; assess willingness to make a quit attempt; assist in quit attempt; and arrange follow-up" (77, p. 39). However, data show that few physicians follow these guidelines (68). In addition, physicians often do not promote smoking cessation interventions for their patients; a survey of physicians in family medicine, general internal medicine, obstetrics/gynecology, and psychiatry found that although $86 \%$ of providers surveyed "usually" advise patients to stop smoking, only $68 \%$ "usually" discuss pharmacotherapies, 37\% talk about counseling options, and31\%recommend NRT. Moreover, only one-fourth prescribe other medications or provide brochures and self-help 
materials. About $13 \%$ refer patients to appropriate cessation treatment, and about $7 \%$ refer their patients to a quitline (5).

Although many smoking cessation interventions have proven to be effective and costeffective in different countries and contexts, it is important to assess whether effectiveness and cost-savings from these interventions can be generalized to subgroups that are disproportionally affected by smoking. Several studies have looked at smoking cessation therapy effectiveness in high-risk populations. A randomized-controlled trial of a groupbased tobacco intervention demonstrated that intensive group cognitive-behavioral therapy is an effective intervention in African American smokers (81). Another randomized trial of cognitive-behavioral therapy with and without NRT found that the combined therapy promoted smoking cessation in pregnant women (60). The number of studies measuring effectiveness of tobacco control programs among other groups, however, such as among persons with mental illness and substance abuse disorders who are disproportionately affected by smoking (69), have been limited. Of the 37 studies included in this review, only two studies looked at a disadvantaged group: patients with depression (7) and low-income pregnant women (65). More effectiveness and cost-effectiveness evaluations are needed among high-risk groups to help clinicians and policy makers create sustainable health care systems that will improve the health of these disproportionally affected groups.

The broader literature has suggested that interventions that are less resource-intensive (e.g., self-help materials) were more cost-effective than those that are more resource-intensive (e.g., NRT and doctor's advice) (79). In a review of the economic literature, for example, one researcher notes that as the intensity of smoking cessation interventions increases, "both cost and effectiveness increase, but cost increases more rapidly" (79, p. 538). Despite these trends, however, the same review notes that different types of smokers will be affected differently by alternative interventions; indeed, different categories of smokers (e.g., light/ casual, heavy, dependent) may have significantly different responses to a particular intervention. For example, brief doctor's advice or self-help materials may be most costeffective for smokers already motivated to quit or for those who categorize themselves as casual or light smokers. More intensive interventions [both in terms of human (counseling) and material (pharmacotherapy) resources] may be more cost-effective for smokers who are highly dependent on and addicted to nicotine or are part of a higher-risk group. Two economic studies in this review found that more intensive intervention had lower cost perQALY (23) or lower incremental cost per life year saved (71) compared with less-intense interventions. Future studies may provide more helpful information by comparing costeffectiveness of interventions for smokers in different categories.

This study attempts to review the available economic evaluations on pharmaco- and behavioral smoking cessation therapies in a systematic and transparent way. We review the evidence base to help public health practitioners better understand CEAs of smoking cessation programs and their useful role in identifying high-quality programs that provide value for money. We also highlight important cost and cost-effectiveness data on smoking cessation programs that can aid decisions for sustainable health care systems. More transparency of economic evaluation methodology (55) and a continued movement to improve the quality and comparability of economic evaluations are needed if policy makers, clinicians, and the public are to employ economic evaluations in decision making (62).

This review has several limitations. First, our literature search was conducted using key words to identify appropriate studies and may have missed some relevant articles that were not picked up from database searches. Second, our analysis was limited to economic studies assessing specific pharmacotherapies and brief counseling for smoking cessation and does not include other programs. Third, considerable heterogeneity among study methods, 
interventions, outcome variables, and cost components limits our ability to compare studies directly and determine specific policy recommendations.

\section{CONCLUSION}

Economic evaluations of pharmaco- and behavioral smoking cessation therapies show that such interventions are both effective and cost-effective. However, there is a need for continued efforts to address methodological challenges related to cost components and outcome measures of economic evaluations. Such efforts will eventually lead to more standardization in economic evaluations and improve generalizability and comparability of economic evaluations of smoking cessation interventions, rendering them more useful to public health practitioners and policy makers. Cost analyses and cost-minimization analyses can aid in examining the least costly approach to achieve public health and medical goals (62). CEA is best used to compare interventions for a single population, such as smokers, by weighing the marginal benefits and marginal costs of alternative interventions (62). The use of CEA for broader societal-level resource allocation through, for example, the use of "league tables," is not advised. Greater transparency and rigorous analysis of economic evaluations will help gain the trust of policy makers and improve the input economic evaluations have on policy and resource-allocation decisions.

\section{Acknowledgments}

Dr. Ruger was supported in part by a Career Development Award from the U.S. National Institutes of Health (grant K01DA016358) and an Investigator Award from the Patrick and Catherine Weldon Donaghue Medical Research Foundation (grant DF06-112). We thank Nora Ng for research and editing assistance.

\section{Glossary}

NRT

nicotine replacement therapy

QALYS

qualityadjusted life years

BENESCO

benefits of smoking cessation on outcomes

\section{LITERATURE CITED}

1. Akers L, Severson HH, Andrews JA, Lichtenstein E. Cost-effectiveness of self-help smokeless tobacco cessation programs. Nicotine Tob. Res. 2007; 9(9):907-914. [PubMed: 17763106]

2. An LC, Schillo BA, Kavanaugh AM, Lachter RB, Luxenberg MG, et al. Increased reach and effectiveness of a statewide tobacco quitline after the addition of access to free nicotine replacement therapy. Tob. Control. 2006; 15(4):286-293. [PubMed: 16885577]

3. Annemans L, Nackaerts K, Bartsch P, Prignot J, Marbaix S. Cost effectiveness of varenicline in Belgium, compared with bupropion, nicotine replacement therapy, brief counselling and unaided smoking cessation: a BENESCO Markov cost-effectiveness analysis. Clin. Drug Investig. 2009; 29(10):655-665.

4. Antoñanzas F, Portillo F. Economic evaluation of pharmacotherapies for smoking cessation. Gac. Sanit. 2003; 17(5):393-403. [PubMed: 14599422]

5. Assoc. Am. Med. Coll.. Physician Behavior and Practice Patterns Related to Smoking Cessation. Washington, DC: AAMC; 2007. http://www.legacyforhealth.org/PDFPublications/ Physicians_Study_-_Legacy_Report.pdf

6. Banta HD, de Wit GA. Public health services and cost-effectiveness analysis. Annu. Rev. Public Health. 2008; 29:383-397. [PubMed: 18173390]

7. Barnett PG, Wong W, Hall S. The cost-effectiveness of a smoking cessation program for outpatients in treatment for depression. Addiction. 2008; 103(5):834-840. [PubMed: 18412763] 
8. Berlin I, Saïd S, Spreux-Varoquaux O, Launay JM, Olivares R, et al. A reversible monoamine oxidase A inhibitor (moclobemide) facilitates smoking cessation and abstinence in heavy, dependent smokers. Clin. Pharmacol. Ther. 1995; 58(4):444-452. [PubMed: 7586937]

9. Bolin K, Lindgren B, Willers S. The cost utility of bupropion in smoking cessation health programs: simulation model results for Sweden. Chest. 2006; 129(3):651-660. [PubMed: 16537864]

10. Bolin K, Mork AC, Wilson K. Smoking-cessation therapy using varenicline: the cost-utility of an additional 12-week course of varenicline for the maintenance of smoking abstinence. J. Eval. Clin. Pract. 2009; 15(3):478-485. [PubMed: 19536915]

11. Bolin K, Wilson K, Benhaddi H, de Nigris E, Marbaix S, et al. Cost-effectiveness of varenicline compared with nicotine patches for smoking cessation-results from four European countries. Eur. J. Public Health. 2009; 19(6):650-654. [PubMed: 19491286]

12. Boyd KA, Briggs AH. Cost-effectiveness of pharmacy and group behavioural support smoking cessation services in Glasgow. Addiction. 2009; 104(2):317-325. [PubMed: 19149829]

13. Brauer CA, Neumann PJ, Rosen AB. Trends in cost effectiveness analyses in orthopaedic surgery. Clin. Orthop. Relat. Res. 2007; 457:42-48. [PubMed: 17242614]

14. Brauer CA, Rosen AB, Greenberg D, Neumann PJ. Trends in the measurement of health utilities in published cost-utility analyses. Value Health. 2006; 9:213-218. [PubMed: 16903990]

15. Brownson RC, Fielding JE, Maylahn CM. Evidence-based public health: a fundamental concept for public health practice. Annu. Rev. Public Health. 2009; 30:175-201. [PubMed: 19296775]

16. Bryson HM, Milne RJ, Chrisp P. Selegiline: an appraisal of the basis of its pharmacoeconomic and quality-of-life benefits in Parkinson's disease. Pharmacoeconomics. 1992; 2(2):118-136. [PubMed: 10146952]

17. Carande-Kulis VG, Maciosek MV, Briss PA, Teutsch SM, Zaza S, Truman BI, et al. Methods for systematic reviews of economic evaluations for the Guide to Community Preventive Services. Am. J. Prev. Med. 2000; 18(1 Suppl):75-91. [PubMed: 10806980]

18. Cent. Dis. Control Prev. Annual smoking-attributable mortality, years of potential life lost, and economic costs-United States, 1995-1999. MMWR. 2002; 51(14):300-303. http://www.cdc.gov/ mmwr/preview/mmwrhtml/mm5114a2.htm. [PubMed: 12002168]

19. Cent. Dis. Control Prev. Cigarette smoking-attributable morbidity-United States, 2000. MMWR. 2003; 52(35):842-844. http://www.cdc.gov/mmwr/preview/mmwrhtml/mm5235a4.htm. [PubMed: 12966360]

20. Cent. Dis. Control Prev. Smoking-attributable mortality, years of potential life lost, and productivity losses-United States, 2000-2004. MMWR. 2008; 57(45):1226-1228. http:// www.cdc.gov/mmwr/preview/mmwrhtml/mm5745a3.htm. [PubMed: 19008791]

21. Cornuz J, Gilbert A, Pinget C, McDonald P, Slama K, et al. Cost-effectiveness of pharmacotherapies for nicotine dependence in primary care settings: a multinational comparison. Tob. Control. 2006; 15(3):152-159. [PubMed: 16728744]

22. Crealey GE, McElnay JC, Maguire TA, O’Neill C. Costs and effects associated with a community pharmacy-based smoking-cessation programme. Pharmacoeconomics. 1998; 14(3):323-333. [PubMed: 10186470]

23. Cromwell J, Bartosch WJ, Fiore MC, Hasselblad V, Baker T. Cost-effectiveness of the clinical practice recommendations in the AHCPR guideline for smoking cessation. JAMA. 1997; 278(21): 1759-1766. [PubMed: 9388153]

24. Cummings SR, Rubin SM, Oster G. The cost-effectiveness of counseling smokers to quit. JAMA. 1989; 261(1):75-79. [PubMed: 2491762]

25. Dino G, Horn K, Abdulkadri A, Kalsekar I, Branstetter S. Cost-effectiveness analysis of the Not On Tobacco program for adolescent smoking cessation. Prev. Sci. 2008; 9(1):38-46. [PubMed: 18286372]

26. Drummond MF, Jefferson TO. Guidelines for authors and peer reviewers of economic submissions to the BMJ. BMJ. 1996; 313:275-283. [PubMed: 8704542]

27. Drummond, MF.; O’Brien, BJ.; Stoddart, GL.; Torrance, GW. Methods for the Economic Evaluation of Health Care Programmes. New York: Oxford Univ. Press; 1997. 
28. Edwards NB, Murphy JK, Downs AD, Ackerman BJ, Rosenthal TL. Doxepin as an adjunct to smoking cessation: a double-blind pilot study. Am. J. Psychiatry. 1989; 146(3):373-376. [PubMed: 2645796]

29. Eisenberg MJ, Filion KB, Yavin D, Belisle P, Mottillo S, et al. Pharmacotherapies for smoking cessation: a meta-analysis of randomized controlled trials. CMAJ. 2008; 179(2):135-144. [PubMed: 18625984]

30. Feenstra TL, Hamberg-van Reenen HH, Hoogenveen RT, Rutten-van Mölken MP. Costeffectiveness of face-to-face smoking cessation interventions: a dynamic modeling study. Value Health. 2005; 8(3):178-190. [PubMed: 15877590]

31. Fellows JL, Bush T, McAfee T, Dickerson J. Cost effectiveness of the Oregon quitline "free patch initiative”. Tob. Control. 2007; 16(Suppl. 1):i47-i52. [PubMed: 18048632]

32. Fiscella K, Franks P. Cost-effectiveness of the transdermal nicotine patch as an adjunct to physicians' smoking cessation counseling. JAMA. 1996; 275(16):1247-1251. [PubMed: 8601956]

33. Folland, S.; Goodman, A.; Stano, M. Economics of Health and Health Care. 5th ed.. Upper Saddle River, NJ: Prentice Hall; 2006.

34. Franco OH, der Kinderen AJ, De Laet C, Peeters A, Bonneux L. Primary prevention of cardiovascular disease: cost-effectiveness comparison. Int. J. Technol. Assess Health Care. 2007; 23(1):71-79. [PubMed: 17234019]

35. Giacomini M, Miller F, O'Brien BJ. Economic considerations for health insurance coverage of emerging genetic tests. Commun. Genet. 2003; 6:61-73.

36. Gilbert AR, Pinget C, Bovet P, Cornuz J, Shamlaye C, Paccaud F. The cost effectiveness of pharmacological smoking cessation therapies in developing countries: a case study in the Seychelles. Tob. Control. 2004; 13(2):190-195. [PubMed: 15175539]

37. Glassman AH, Covey LS, Dalack GW, Stetner F, Rivelli SK, et al. Smoking cessation, clonidine, and vulnerability to nicotine among dependent smokers. Clin. Pharmacol. Ther. 1993; 54(6):670679. [PubMed: 8275622]

38. Gold, MR.; Siegel, JE.; Russell, LB.; Weinstein, MC., editors. Cost-Effectiveness in Health and Medicine. New York: Oxford Univ. Press; 1996.

39. Grosse SD, Teutsch SM, Haddix AC. Lessons from cost-effectiveness research for United States public health policy. Annu. Rev. Public Health. 2007; 28:365-391. [PubMed: 17222080]

40. Haile MJ, Wiggers JH, Spigelman AD, Knight J, Considine RJ, Moore K. Novel strategy to stop cigarette smoking by surgical patients: pilot study in a preadmission clinic. ANZ J. Surg. 2002; 72(9):618-622. [PubMed: 12269908]

41. Hall SM, Reus VI, Muñoz RF, Sees KL, Humfleet G, et al. Nortriptyline and cognitive-behavioral therapy in the treatment of cigarette smoking. Arch. Gen. Psychiatry. 1998; 55(8):683-690. [PubMed: 9707377]

42. Halpern MT, Dirani R, Schmier JK. The cost effectiveness of varenicline for smoking cessation. Manag. Care Interface. 2007; 20(10):18-25. [PubMed: 18405203]

43. Hempel AG, Wagner ML, Maaty MA, Sage JI. Pharmacoeconomic analysis of using Sinemet CR over standard Sinemet in Parkinsonian patients with motor fluctuations. Ann. Pharmacother. 1998; 32(9):878-883. [PubMed: 9762373]

44. Hilleman DE, Mohiuddin SM, Delcore MG, Lucas BD Jr. Randomized, controlled trial of transdermal clonidine for smoking cessation. Ann. Pharmacother. 1993; 27(9):1025-1028. [PubMed: 8219431]

45. Hollis JF, McAfee TA, Fellows JL, Zbikowski SM, Stark M, Riedlinger K. The effectiveness and cost effectiveness of telephone counselling and the nicotine patch in a state tobacco quitline. Tob. Control. 2007; 16(Suppl 1):i53-i59. [PubMed: 18048633]

46. Hoogendoorn M, Welsing P, Rutten-van Mölken MP. Cost-effectiveness of varenicline compared with bupropion, NRT, and nortriptyline for smoking cessation in the Netherlands. Curr. Med. Res. Opin. 2008; 24(1):51-61. [PubMed: 18021492]

47. Howard P, Knight C, Boler A, Baker C. Cost-utility analysis of varenicline versus existing smoking cessation strategies using the BENESCO simulation model: application to a population of US adult smokers. Pharmacoeconomics. 2008; 26(6):497-511. [PubMed: 18489200] 
48. Igarashi A, Takuma H, Fukuda T, Tsutani K. Cost-utility analysis of varenicline, an oral smokingcessation drug, in Japan. Pharmacoeconomics. 2009; 27(3):247-261. [PubMed: 19354344]

49. Jackson KC 2nd, Nahoopii R, Said Q, Dirani R, Brixner D. An employer-based cost-benefit analysis of a novel pharmacotherapy agent for smoking cessation. J. Occup. Environ. Med. 2007; 49(4):453-460. [PubMed: 17426529]

50. Jefferson T, Demicheli V, Vale L. Quality of systematic reviews of economic evaluations in health care. JAMA. 2002; 287:2809-2812. [PubMed: 12038919]

51. Knight C, Howard P, Baker CL, Marton JP. The cost-effectiveness of an extended course (12 weeks) of varenicline compared with other available smoking cessation strategies in the United States: an extension and update to the BENESCO model. Value Health. 2010; 13(2):209-214. [PubMed: 19912599]

52. Meenan RT, Stevens VJ, Hornbrook MC, La Chance PA, Glasgow RE, et al. Cost-effectiveness of a hospital-based smoking cessation intervention. Med. Care. 1998; 36(5):670-678. [PubMed: 9596058]

53. Moher D, Cook DJ, Eastwood S, Olkin I, Rennie D, Stroup DF. Improving the quality of reports of meta-analyses of randomised controlled trials: the QUOROM statement. Lancet. 1999; 354:18961900. [PubMed: 10584742]

54. Mullen PD, Ramirez G. The promise and pitfalls of systematic reviews. Annu. Rev. Public Health. 2006; 27:81-102. [PubMed: 16533110]

55. Neumann, PJ. Using Cost-Effectiveness Analysis to Improve Health Care. New York: Oxford; 2005.

56. Neumann PJ, Fang CH, Cohen JT. 30 years of pharmaceutical cost-utility analyses: growth, diversity, and methodological improvement. Pharmacoeconomics. 2009; 27(10):861-872. [PubMed: 19803540]

57. Neumann PJ, Greenberg D, Olchanski NV, Stone PW, Rosen AB. Growth and quality of the costutility literature, 1976-2001. Value Health. 2005; 8:3-9. [PubMed: 15841889]

58. Neumann PJ, Stone PW, Chapman RH, Sandberg EA, Bell CM. The quality of reporting in published cost-utility analyses, 1976-1997. Ann. Intern. Med. 2000; 132:964-972. [PubMed: 10858180]

59. Oster G, Huse DM, Delea TE, Colditz GA. Cost-effectiveness of nicotine gum as an adjunct to physician's advice against cigarette smoking. JAMA. 1986; 256(10):1315-1318. [PubMed: 3091857]

60. Pollak KI, Oncken CA, Lipkus IM, Lyna P, Swamy GK, et al. Nicotine replacement and behavioral therapy for smoking cessation in pregnancy. Am. J. Prev. Med. 2007; 33(4):297-305. [PubMed: 17888856]

61. Ranney L, Melvin C, Lux L, McClain E, Lohr KN. Systematic review: smoking cessation intervention strategies for adults and adults in special populations. Ann. Intern. Med. 2006; 145(11):845-856. [PubMed: 16954352]

62. Ruger, JP. Health and Social Justice. Oxford: Clarendon; 2009.

63. Ruger JP, Emmons KM. Economic evaluations of smoking cessation and relapse prevention programs for pregnant women: a systematic review. Value Health. 2008; 11(2):180-190. [PubMed: 17854435]

64. Ruger JP, Lazar CM. Economic evaluation of drug abuse treatment and HIV prevention programs in pregnant women: A systematic review. Addict. Behav. 2012; 37(1):1-10. [PubMed: 21962429]

65. Ruger JP, Weinstein MC, Hammond SK, Kearney MH, Emmons KM. Cost-effectiveness of motivational interviewing for smoking cessation and relapse prevention among low-income pregnant women: a randomized controlled trial. Value Health. 2008; 11(2):191-198. [PubMed: 17854434]

66. Saha S, Hoerger TJ, Pignone MP, Teutsch SM, Helfand M, Mandelblatt JS. Cost Work Group of the Third U.S. Preventive Services Task Force. The art and science of incorporating cost effectiveness into evidence-based recommendations for clinical preventive services. Am. J. Prev. Med. 2001; 20(3 Suppl):36-43. [PubMed: 11306230] 
67. Salize HJ, Merkel S, Reinhard I, Twardella D, Mann K, Brenner H. Cost-effective primary carebased strategies to improve smoking cessation: more value for money. Arch. Intern. Med. 2009; 169(3):230-235. [PubMed: 19204212]

68. Schroeder SA. What to do with a patient who smokes. JAMA. 2005; 294(4):482-487. [PubMed: 16046655]

69. Schroeder SA, Morris CD. Confronting a neglected epidemic: tobacco cessation for persons with mental illnesses and substance abuse problems. Annu. Rev. Public Health. 2010; 31:297-314. [PubMed: 20001818]

70. Solberg LI, Maciosek MV, Edwards NM, Khanchandani HS, Goodman MJ. Repeated tobacco-use screening and intervention in clinical practice: health impact and cost effectiveness. Am. J. Prev. Med. 2006; 31(1):62-71. [PubMed: 16777544]

71. Song F, Raftery J, Aveyard P, Hyde C, Barton P, Woolacott N. Cost-effectiveness of pharmacological interventions for smoking cessation: a literature review and a decision analytic analysis. Med. Decis. Making. 2002; 22(5 Suppl):S26-S37. [PubMed: 12369228]

72. Stapleton JA, Lowin A, Russell MA. Prescription of transdermal nicotine patches for smoking cessation in general practice: evaluation of cost-effectiveness. Lancet. 1999; 354(9174):210-215. [PubMed: 10421303]

73. Stone PW, Teutsch SM, Chapman RH, Bell C, Goldie SJ, Neumann PJ. Cost-utility analyses of clinical preventive services: published ratios, 1976-1997. Am. J. Prev. Med. 2000; 19:15-23. [PubMed: 10865159]

74. Thacker SB, Ikeda RM, Gieseker KE, Mendelsohn AB, Saydah SH, et al. The evidence base for public health: informing policy at the Centers for Disease Control and Prevention. Am. J. Prev. Med. 2005; 28:227-233. [PubMed: 16168874]

75. Thavorn K, Chaiyakunapruk N. A cost-effectiveness analysis of a community pharmacist-based smoking cessation programme in Thailand. Tob. Control. 2008; 17(3):177-182. [PubMed: 18285385]

76. Tran MT, Holdford DA, Kennedy DT, Small RE. Modeling the cost-effectiveness of a smokingcessation program in a community pharmacy practice. Pharmacotherapy. 2002; 22(12):1623-1631. [PubMed: 12495172]

77. U.S. Dep. Health Hum. Serv.. Clinical Practice Guideline: Treating Tobacco Use and Dependence: 2008 Update. Washington, DC: US Dep. Health Hum. Serv.; 2008. http:// www.surgeongeneral.gov/tobacco/treating_tobacco_use08.pdf

78. U. K. Natl.Health Serv. Cent.Rev. Dissem.. Undertaking Systematic Reviews of Research on Effectiveness: CRD's Guidance For Those Carrying Out or Commissioning Reviews. 2nd ed.. York: Univ. York; 2001. CRD Rep. 4, March. http://www.medepi.net/meta/guidelines/ Overview_CRD_Guidelines.pdf

79. Warner KE. Cost effectiveness of smoking-cessation therapies. Interpretation of the evidence-and implications for coverage. Pharmacoeconomics. 1997; 11(6):538-549. [PubMed: 10168094]

80. Wasley MA, McNagny SE, Phillips VL, Ahluwalia JS. The cost-effectiveness of the nicotine transdermal patch for smoking cessation. Prev. Med. 1997; 26(2):264-270. [PubMed: 9085397]

81. Webb MS, Rodriguez de Ybarra D, Baker EA, Reis IM, Carey MP. Cognitive-behavioral therapy to promote smoking cessation among African American smokers: a randomized clinical trial. J. Consult. Clin. Psychol. 2010; 78(1):24-33. [PubMed: 20099947]

82. World Health Organ. (WHO). The tobacco atlas. Tobacco Free Initiative; 2004. http:// www.who.int/tobacco/en/atlas 13.pdf

\section{RELATED RESOURCES}

Brownson RC, Hopkins DP, Wakefield MA. Effects of smoking restrictions in the workplace. Annu. Rev. Public Health. 2002; 23:333-348. [PubMed: 11910066]

Cummings KM, Hyland A. Impact of nicotine replacement therapy on smoking behavior. Annu. Rev. Public Health. 2005; 26:583-599. [PubMed: 15760302]

Curry SJ, Keller PA, Orleans CT, Fiore MC. The role of health care systems in increased tobacco cessation. Annu. Rev. Public Health. 2008; 29:411-428. [PubMed: 18173387] 
Curry SJ, Mermelstein RJ, Sporer AK. Therapy for specific problems: youth tobacco cessation. Annu. Rev. Psychol. 2009; 60:229-255. [PubMed: 19035825]

Fischer EB, Lichtenstein E, Haire-Joshu D, Morgan GL, Rehberg HR. Methods, successes, and failures of smoking cessation programs. Annu. Rev. Med. 1993; 44:481-513. [PubMed: 8476266]

Siu EC, Tyndale RF. Non-nicotinic therapies for smoking cessation. Annu. Rev. Pharmacol. Toxicol. 2007; 47:541-564. [PubMed: 17209799] 


\section{SUMMARY POINTS}

1. Cost analyses provide important information on evidence-based public health programs while helping to improve decision making.

2. Economic evaluations of smoking cessation therapies demonstrate that programs vary greatly in cost-effectiveness depending on contextual factors. However, smoking cessation intervention cost-effective ratios compare favorably with other health care interventions.

3. Standardization of economic evaluations will make future studies more comparable.

4. More transparency of economic evaluation methodology and continued efforts to improve the quality and comparability of economic evaluations are needed if policy makers are to effectively employ these analyses in decision making. 


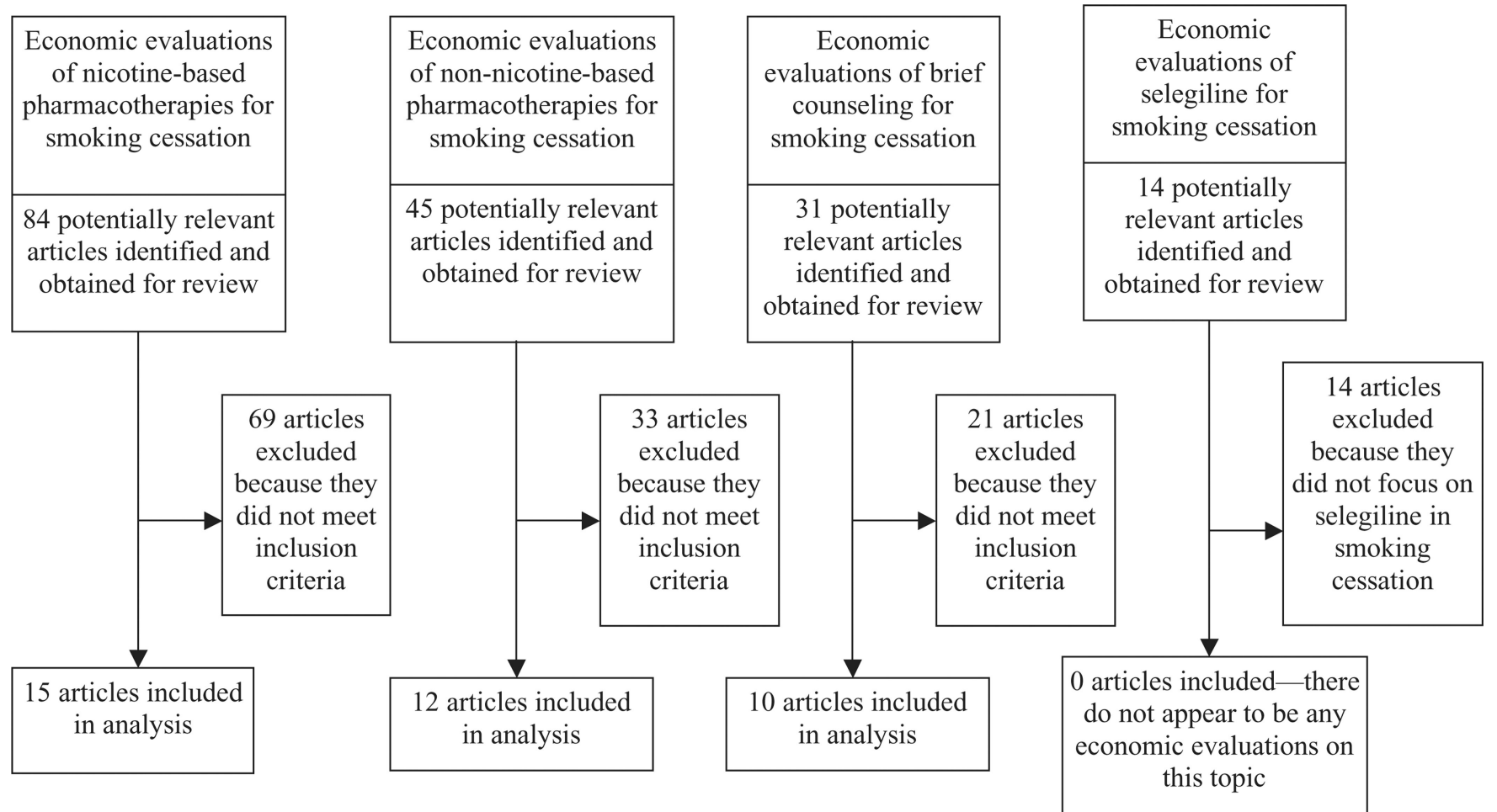

Figure 1.

Flow chart of study selection process. 
Table 1

Interventions for smoking cessation

\begin{tabular}{|c|c|c|c|}
\hline First-line drugs & Second-line drugs & $\begin{array}{l}\text { Other drugs not FDA } \\
\text { approved for smoking } \\
\text { cessation }\end{array}$ & Behavioral therapies \\
\hline Nicotine-based medications & Clonidine & Fluoxetine & Partner support \\
\hline Nicotine patch & & Paroxetine & Psychological counseling \\
\hline Nicotine inhaler & & Naltrexone & - Telephone counseling \\
\hline Nicotine nasal spray & & Rimonabant & - Professional advice \\
\hline Antagonist (e.g., bupropion) & & Selegiline & \\
\hline Partial agonist (e.g., varenicline) & & & \\
\hline
\end{tabular}


Table 2

Types of economic evaluations. Adapted from Drummond et al. (27)

\begin{tabular}{l}
\hline 1. Cost minimization analysis: searches for the least costly alternative producing same health benefits \\
\hline 2. Cost effectiveness analysis: compares per unit effect with per unit cost on an incremental basis \\
\hline 3. Cost benefit analysis: measures both the costs and consequences of alternatives in monetary units \\
\hline 4. Cost utility analysis: type of cost-effectiveness analysis that employs utilities (e.g., quality-adjusted life years) to evaluate a program \\
\hline
\end{tabular}


Table 3

Data extracted from included articles. Reprinted from Ruger \& Emmons (63)

\begin{tabular}{l}
\hline 1. Author \\
\hline 2. Years of study \\
\hline 3. Topic and study questions \\
\hline 4. Setting \\
\hline 5. Type of economic analysis \\
\hline 6. Year of publication \\
\hline 7. Intervention type \\
\hline 8. Health outcomes \\
\hline 9. Methods used to define effectiveness and preferences: time trade-off, standard gamble or rating scale, source of weights \\
\hline 10. Resource and cost estimates: net costs, gross- or microcosting, year, currency \\
\hline 11. Inclusion of original analyses \\
\hline 12. Study perspective \\
\hline 13. Description of comparator intervention \\
\hline 14. Study assumptions \\
\hline 15. Study type and design: clinical trial, observational study, decision analytical model \\
\hline 16. Modeling assumptions \\
\hline 17. Variable estimates \\
\hline 18. Discounting \\
\hline 19. Sensitivity analyses performed: for costs, effectiveness, preference weights, discount rate \\
\hline 20. Funding source \\
21. Comparison with other economic evaluations \\
\hline
\end{tabular}




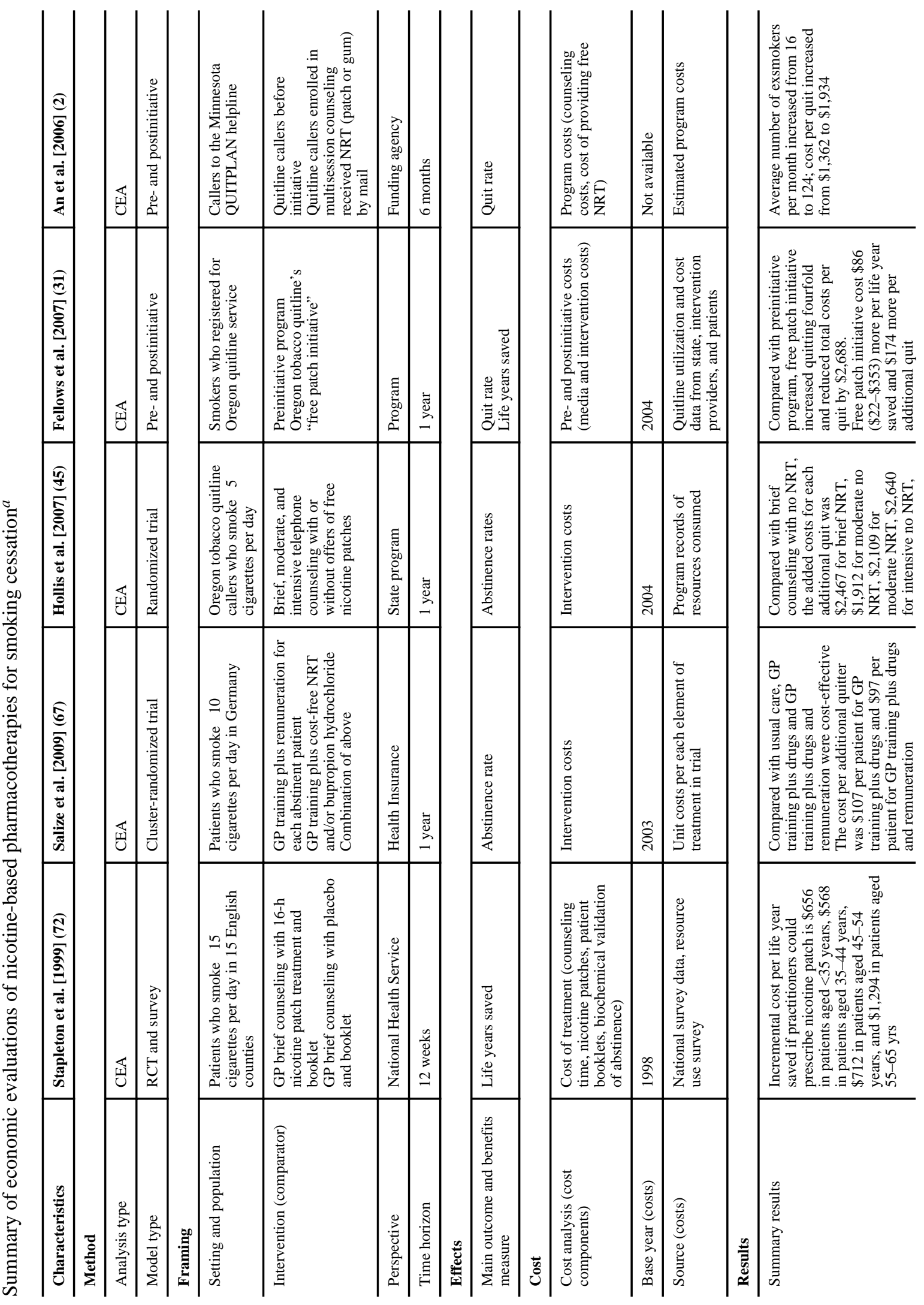




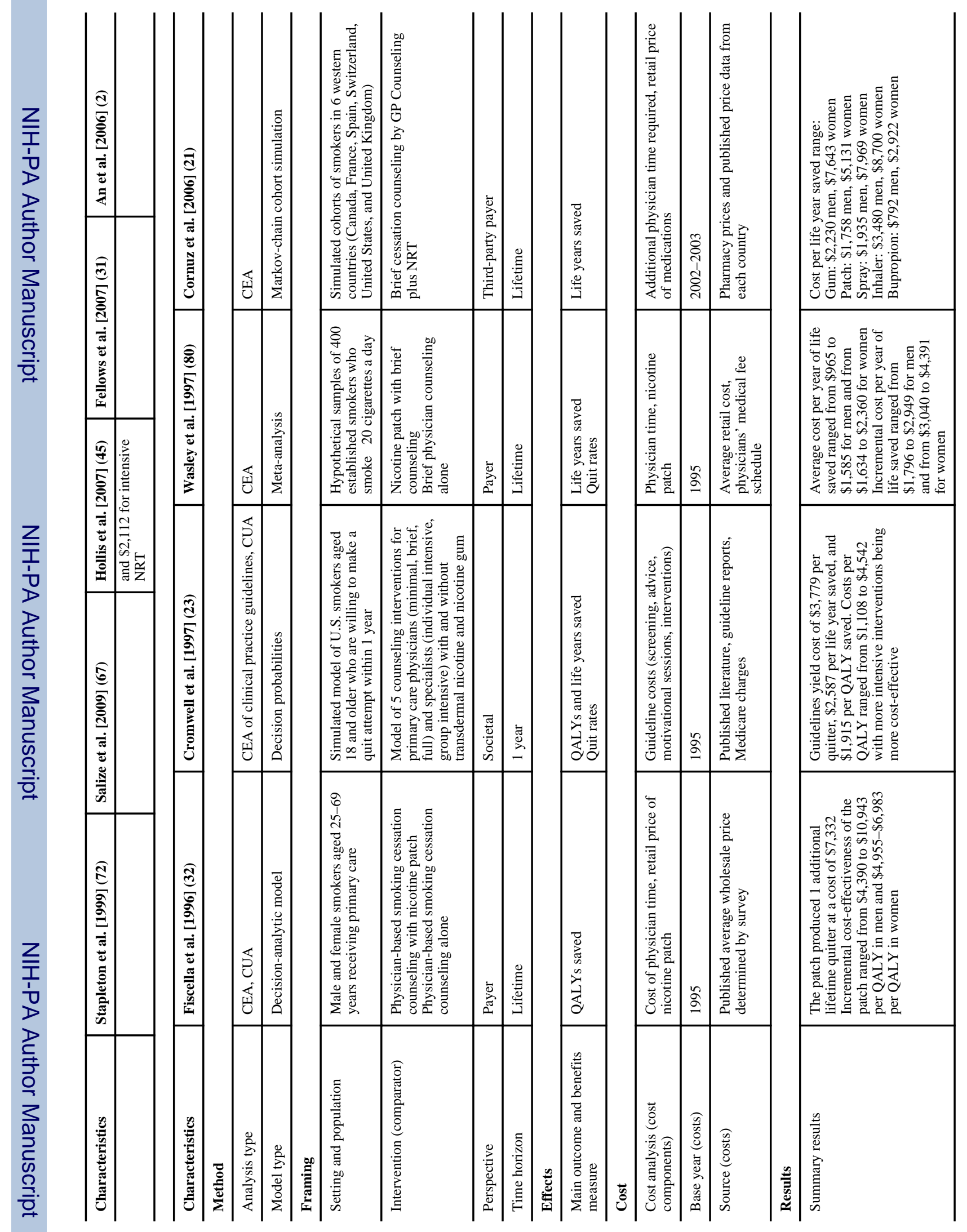




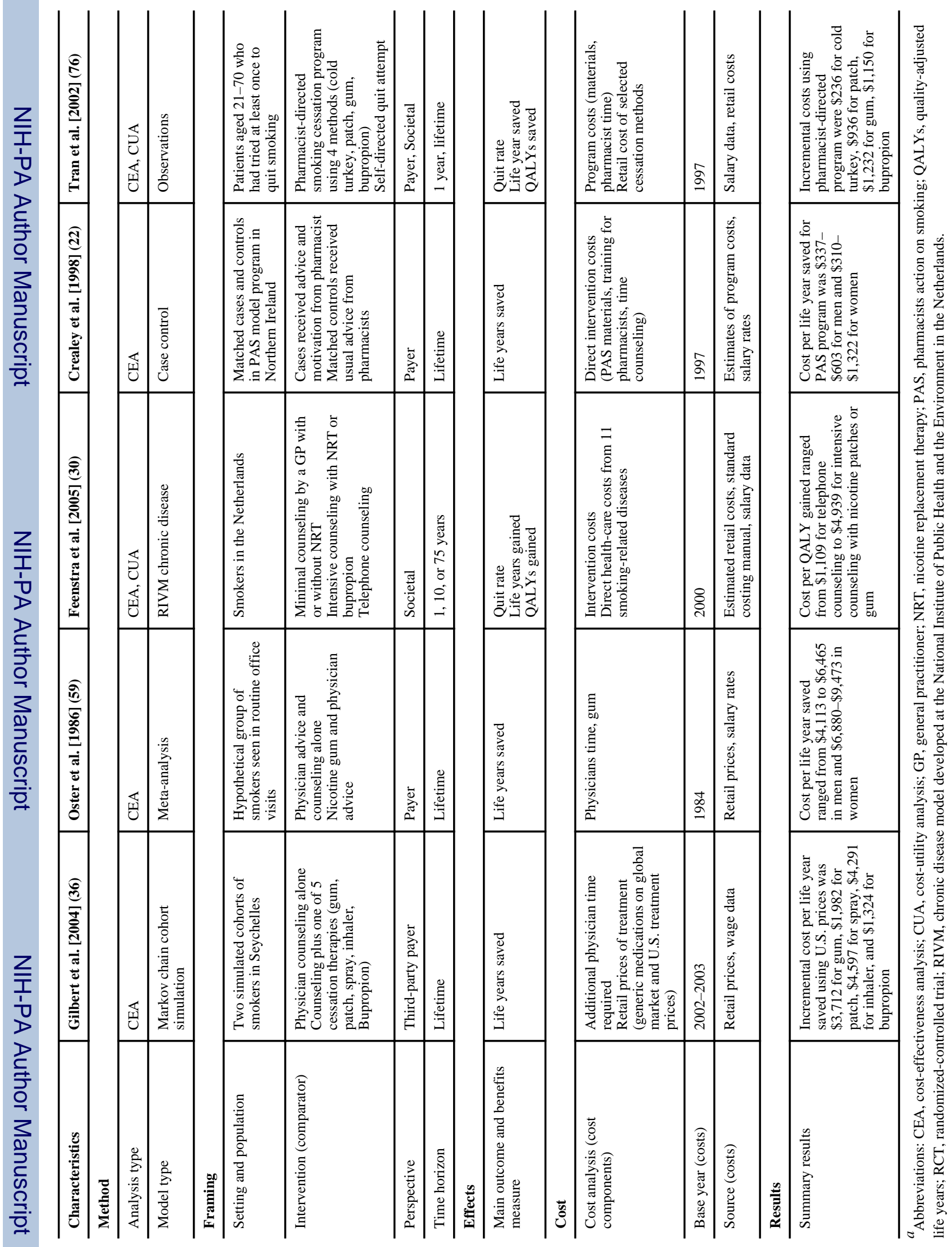


Table 5

Summary of economic evaluations of nonnicotine-based pharmacotherapies for smoking cessation ${ }^{a}$

\begin{tabular}{|c|c|c|c|c|}
\hline Characteristics & $\begin{array}{l}\text { Hoogendoorn et } \\
\text { al. [2007] (46) }\end{array}$ & Annemans et al. [2009] (3) & Bolin et al. [2009] (11) & Howard et al. [2008] (47) \\
\hline \multicolumn{5}{|l|}{ Method } \\
\hline Analysis type & CEA, CUA & CEA, CUA & CEA, CUA & CUA \\
\hline Model type & BENESCO model & BENESCO Markov simulation & BENESCO Markov simulation & BENESCO Markov simulation \\
\hline \multicolumn{5}{|l|}{ Framing } \\
\hline Setting and population & $\begin{array}{l}\text { Hypothetical } \\
\text { cohort of Dutch } \\
\text { smokers making a } \\
\text { one-time quit } \\
\text { attempt }\end{array}$ & $\begin{array}{l}\text { Cohort of Belgian adult } \\
\text { smokers making a one-time } \\
\text { quit attempt }\end{array}$ & $\begin{array}{l}\text { Simulated model of four } \\
\text { European countries (Belgium, } \\
\text { France, Sweden, and United } \\
\text { Kingdom) }\end{array}$ & $\begin{array}{l}\text { Hypothetical cohort of U.S. } \\
\text { adult smokers who make a } \\
\text { one-time quit attempt }\end{array}$ \\
\hline Intervention (comparator) & $\begin{array}{l}\text { Varenicline } \\
\text { Untreated or } \\
\text { treated with } \\
\text { bupropion, } \\
\text { nortriptyline, or } \\
\text { NRT }\end{array}$ & $\begin{array}{l}\text { Varenicline, Bupropion, or } \\
\text { NRT with brief counseling } \\
\text { Brief counseling alone } \\
\text { Unaided cessation }\end{array}$ & $\begin{array}{l}\text { Varenicline } \\
\text { NRT }\end{array}$ & $\begin{array}{l}\text { Varenicline } \\
\text { Bupropion } \\
\text { NRT } \\
\text { Unaided quitting }\end{array}$ \\
\hline Perspective & $\begin{array}{l}\text { Dutch health care } \\
\text { system }\end{array}$ & $\begin{array}{l}\text { Health care payer (public and } \\
\text { private) }\end{array}$ & National health care system & U.S. health care system \\
\hline Time horizon & Lifetime & Lifetime & Lifetime & 20 years and lifetime \\
\hline \multicolumn{5}{|l|}{ Effects } \\
\hline $\begin{array}{l}\text { Main outcome and } \\
\text { benefits measure }\end{array}$ & $\begin{array}{l}\text { Quit rate } \\
\text { QALYs gained }\end{array}$ & $\begin{array}{l}\text { Life years gained } \\
\text { QALYs gained }\end{array}$ & $\begin{array}{l}\text { Life years gained } \\
\text { QALYs gained }\end{array}$ & QALYs \\
\hline \multicolumn{5}{|l|}{ Cost } \\
\hline $\begin{array}{l}\text { Cost analysis (cost } \\
\text { components) }\end{array}$ & $\begin{array}{l}\text { Intervention costs } \\
\text { Direct medical } \\
\text { costs of smoking- } \\
\text { related diseases } \\
\text { (COPD, lung } \\
\text { cancer, CHD, } \\
\text { stroke) }\end{array}$ & $\begin{array}{l}\text { Costs of intervention } \\
\text { Direct medical costs related to } \\
\text { smoking comorbidities } \\
\text { (COPD, lung cancer, CHD, } \\
\text { stroke, asthma) }\end{array}$ & $\begin{array}{l}\text { Intervention costs } \\
\text { Morbidity-related health care } \\
\text { costs from } 4 \text { smoking-related } \\
\text { morbidities (lung cancer, } \\
\text { COPD, CHD, and stroke) }\end{array}$ & $\begin{array}{l}\text { Intervention costs } \\
\text { Direct lifetime costs of } \\
\text { smoking-related diseases (lung } \\
\text { cancer, COPD, CHD, stroke, } \\
\text { asthma) }\end{array}$ \\
\hline Base year (costs) & 2004 & 2007 & Not available & 2005 \\
\hline Source (costs) & $\begin{array}{l}\text { Estimates from } \\
\text { Dutch source data }\end{array}$ & $\begin{array}{l}\text { Literature and public health } \\
\text { databases }\end{array}$ & Country-specific databases & $\begin{array}{l}\text { U.S. Red Book, market rates, } \\
\text { literature }\end{array}$ \\
\hline \multicolumn{5}{|l|}{ Results } \\
\hline Summary results & $\begin{array}{l}\text { Varenicline } \\
\text { estimated to cost } \\
\$ 1,472 \text { per QALY } \\
\text { gained compared } \\
\text { with nortriptyline } \\
\text { and } \$ 285 \text { per } \\
\text { QALY gained } \\
\text { compared with } \\
\text { unaided cessation } \\
\text { Cost of } \\
\text { varenicline per } \\
\text { additional quitter } \\
\text { ranged from } \$ 919 \\
\text { compared with } \\
\text { NRT to } \$ 3,809 \\
\text { compared with } \\
\text { nortriptyline }\end{array}$ & $\begin{array}{l}\text { Compared with brief } \\
\text { counseling alone and unaided } \\
\text { cessation, varenicline costs } \\
\$ 337 \text { and } \$ 2,325 \text { per QALY } \\
\text { gained, respectively } \\
\text { Varenicline is cost-saving } \\
\text { compared with bupropion and } \\
\text { NRT }\end{array}$ & $\begin{array}{l}\text { In a typical smoking cessation } \\
\text { intervention, using varenicline } \\
\text { instead of NRT was cost- } \\
\text { saving in all countries except } \\
\text { France, who had a cost- } \\
\text { effectiveness ratio of } \$ 3,936 \\
\text { per QALY gained }\end{array}$ & $\begin{array}{l}\text { Over } 20 \text { years and lifetime, } \\
\text { varenicline dominated } \\
\text { bupropion, NRT, and unaided } \\
\text { cessation }\end{array}$ \\
\hline
\end{tabular}




\begin{tabular}{|c|c|c|c|c|}
\hline Characteristics & Knight et al. [2009] (51) & Bolin et al. [2009] (10) & $\begin{array}{l}\text { Antonanzas \& } \\
\text { Portillo [2003] (4) }\end{array}$ & $\begin{array}{l}\text { Bolin et al. } \\
{[2006](9)}\end{array}$ \\
\hline \multicolumn{5}{|l|}{ Method } \\
\hline Analysis type & CEA, CUA & CUA & CEA & CUA \\
\hline Model type & BENESCO Markov simulation & BENESCO Markov simulation & $\begin{array}{l}\text { Adaptation of HECOS } \\
\text { simulation }\end{array}$ & $\begin{array}{l}\text { Global health } \\
\text { outcomes } \\
\text { simulation } \\
\text { model }\end{array}$ \\
\hline \multicolumn{5}{|l|}{ Framing } \\
\hline Setting and population & $\begin{array}{l}\text { Hypothetical population of } \\
\text { adult American smokers who } \\
\text { make a single quit attempt }\end{array}$ & $\begin{array}{l}\text { Simulated cohort of adult } \\
\text { smokers in Sweden who } \\
\text { successfully abstain after an } \\
\text { initial 12-week treatment of } \\
\text { varenicline }\end{array}$ & Smokers in Spain & $\begin{array}{l}\text { Model cohort } \\
\text { of male and } \\
\text { female smokers } \\
\text { in Sweden }\end{array}$ \\
\hline Intervention (comparator) & $\begin{array}{l}12+12 \text { weeks of varenicline } \\
12 \text { weeks varenicline, } \\
\text { bupropion, NRT, or unaided } \\
\text { cessation }\end{array}$ & $\begin{array}{l}\text { Additional } 12 \text { weeks } \\
\text { varenicline Placebo }\end{array}$ & $\begin{array}{l}\text { Bupropion } \\
\text { NRT (patch or nicotine } \\
\text { gum) }\end{array}$ & $\begin{array}{l}\text { Bupropion } \\
\text { NRT (patches } \\
\text { and gum) }\end{array}$ \\
\hline Perspective & Health care system & Societal & National health system & Societal \\
\hline Time horizon & $5,10,20$ years, lifetime & 50 years & 20 years & 20 years \\
\hline \multicolumn{5}{|l|}{ Effects } \\
\hline $\begin{array}{l}\text { Main outcome and } \\
\text { benefits measure }\end{array}$ & QALYs gained & QALYs gained & $\begin{array}{l}\text { Deaths prevented } \\
\text { Life years saved }\end{array}$ & QALYs gained \\
\hline \multicolumn{5}{|l|}{ Cost } \\
\hline $\begin{array}{l}\text { Cost analysis (cost } \\
\text { components) }\end{array}$ & $\begin{array}{l}\text { Direct treatment costs } \\
\text { Morbidity-related health care } \\
\text { costs of smoking-related } \\
\text { diseases (lung cancer, stroke, } \\
\text { CHD, COPD, and asthma) }\end{array}$ & $\begin{array}{l}\text { Intervention costs } \\
\text { Average direct medical costs } \\
\text { from smoking-related diseases } \\
\text { (COPD, CHD, stroke, lung } \\
\text { cancer) } \\
\text { Average value of indirect } \\
\text { effects (consumption, } \\
\text { production) }\end{array}$ & $\begin{array}{l}\text { Intervention costs } \\
\text { Tobacco-related health } \\
\text { costs (cancers, CHD, } \\
\text { stroke, COPD, low } \\
\text { birth weight) }\end{array}$ & $\begin{array}{l}\text { Intervention } \\
\text { costs } \\
\text { Direct (COPD, } \\
\text { asthma, CHD, } \\
\text { stroke, lung } \\
\text { cancer) and } \\
\text { indirect } \\
\text { (production and } \\
\text { consumption) } \\
\text { effects of } \\
\text { smoking }\end{array}$ \\
\hline Base year (costs) & 2005 & 2003 & 1999 & 2001 \\
\hline Source (costs) & $\begin{array}{l}\text { Literature, } 2005 \text { U.S. Red Book } \\
\text { prices }\end{array}$ & $\begin{array}{l}\text { Health care cost data from } \\
\text { Skane, estimated prescription } \\
\text { prices, published literature }\end{array}$ & $\begin{array}{l}\text { National Health } \\
\text { Survey, National } \\
\text { Institute of Statistics }\end{array}$ & $\begin{array}{l}\text { Swedish unit } \\
\text { costs, hospital } \\
\text { records, } \\
\text { physician } \\
\text { records }\end{array}$ \\
\hline \multicolumn{5}{|l|}{ Results } \\
\hline Summary results & $\begin{array}{l}\text { Additional } 12 \text { weeks of } \\
\text { varenicline dominates all other } \\
\text { strategies except } 12 \text { weeks of } \\
\text { varenicline } \\
\text { Additional } 12 \text { weeks of } \\
\text { varenicline treatment increases } \\
1 \text {-year abstinence rates from } \\
23 \% \text { to } 28 \% \text { (compared with } 12 \\
\text { weeks of varenicline); the } \\
\text { additional } 12 \text { weeks of } \\
\text { varenicline also had an } \\
\text { incremental cost of } \$ 972 \text { per } \\
\text { QALY gained over the lifetime } \\
\text { of all subjects }\end{array}$ & $\begin{array}{l}\text { Incremental costs per QALY } \\
\text { for varenicline compared with } \\
\text { placebo were } \$ 7,420 \text { for men } \\
\text { and } \$ 7,464 \text { for women } \\
\text { Incremental costs per QALY } \\
\text { including indirect effects were } \\
\$ 25,359 \text { for men and } \$ 25,660 \\
\text { for women }\end{array}$ & $\begin{array}{l}\text { At } 20 \text { years for } \\
\text { bupropion and nicotine } \\
\text { patch respectively, } \\
\text { there was a net savings } \\
\text { of } \$ 32,920 \text {, and } \\
\$ 15,993 \text { per death } \\
\text { prevented, and a net } \\
\text { savings of } \$ 3,852 \text { and } \\
\$ 1,867 \text { per life year } \\
\text { saved } \\
\text { At } 20 \text { years, nicotine } \\
\text { gum has a cost- } \\
\text { effectiveness ratio of } \\
\$ 41,325 \text { per death } \\
\text { prevented and } \$ 4,786 \\
\text { per life year saved }\end{array}$ & $\begin{array}{l}\text { Bupropion was } \\
\text { cost-saving } \\
\text { compared with } \\
\text { both NRT } \\
\text { when direct and } \\
\text { indirect effects } \\
\text { on production } \\
\text { and } \\
\text { consumption } \\
\text { were included } \\
\text { When only } \\
\text { direct costs } \\
\text { were included, } \\
\text { incremental } \\
\text { cost per QALY } \\
\text { gained for } \\
\text { bupropion was } \\
\$ 702 \text { (men) and } \\
\$ 521 \text { (women) } \\
\text { compared with }\end{array}$ \\
\hline
\end{tabular}




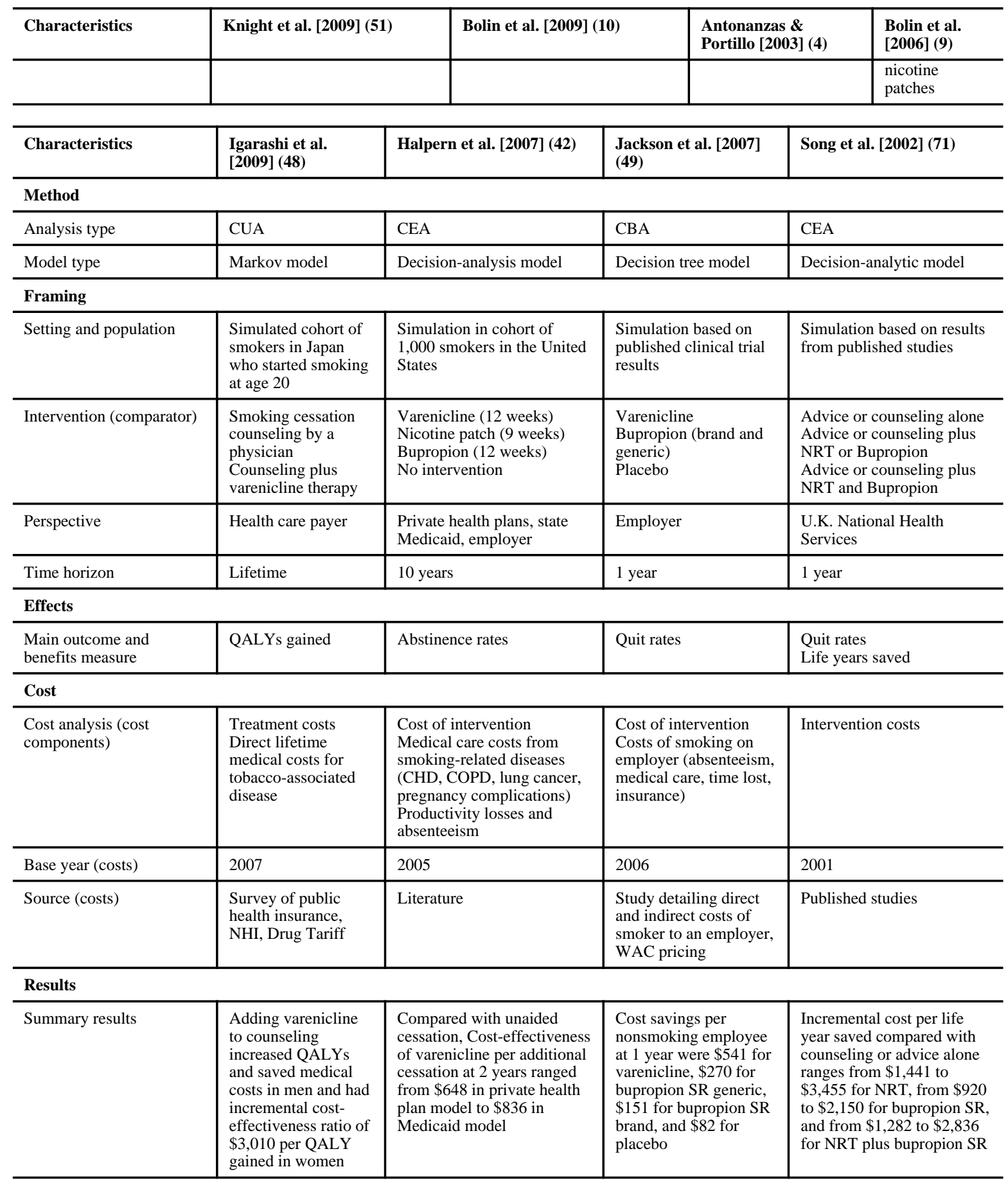

${ }^{a}$ Abbreviations: BENESCO, benefits of smoking cessation on outcomes; CEA, cost-effectiveness analysis; CHD, coronary heart disease; COPD, chronic obstructive pulmonary disease; CUA, cost-utility analysis; HECOS, health and economic consequences of smoking interactive; NHI, National Health Insurance; NRT, nicotine replacement therapy; QALYs, quality-adjusted life years; SR, sustained release; WAC, wholesale acquisition costs. 


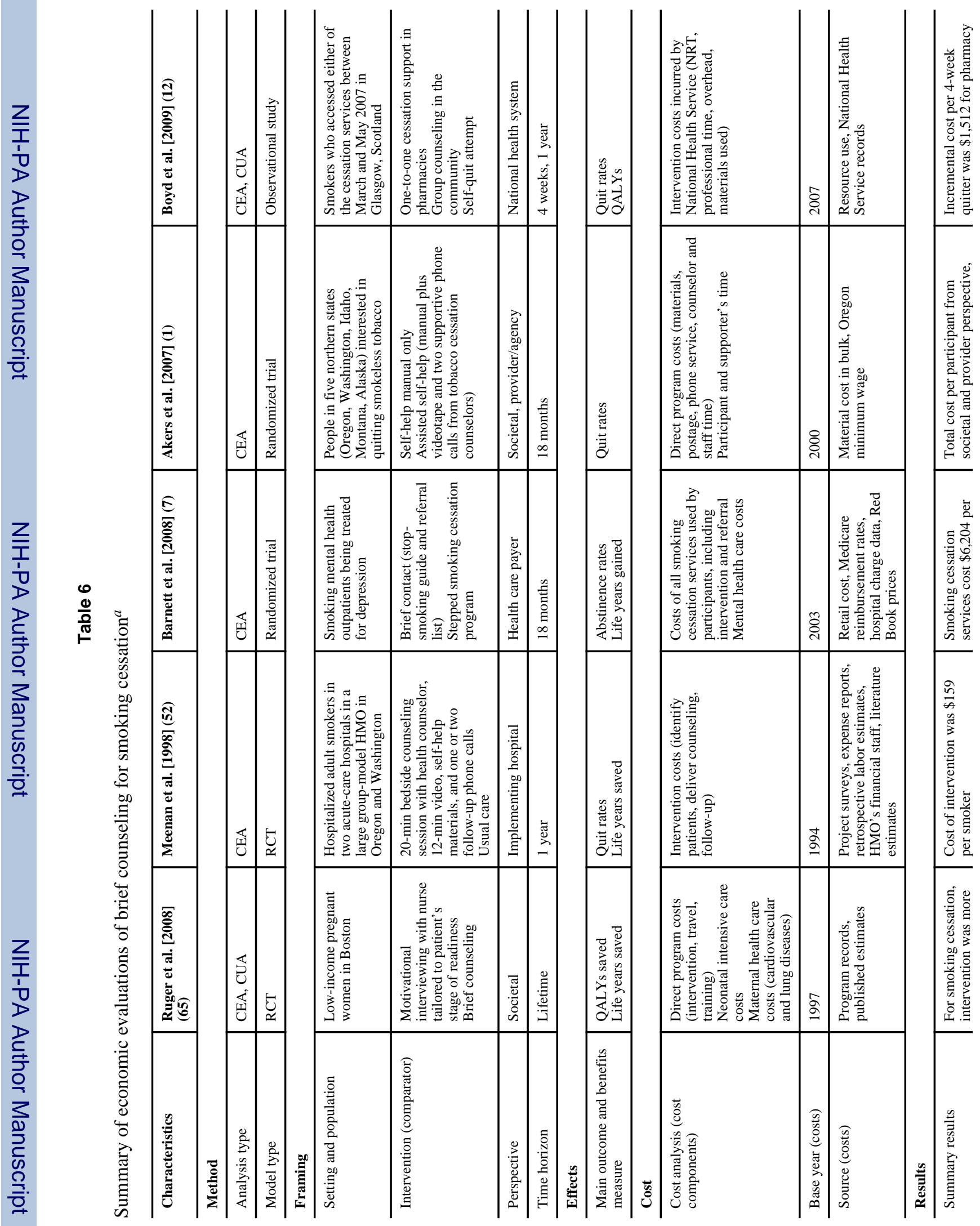


Ruger and Lazar

Page 31

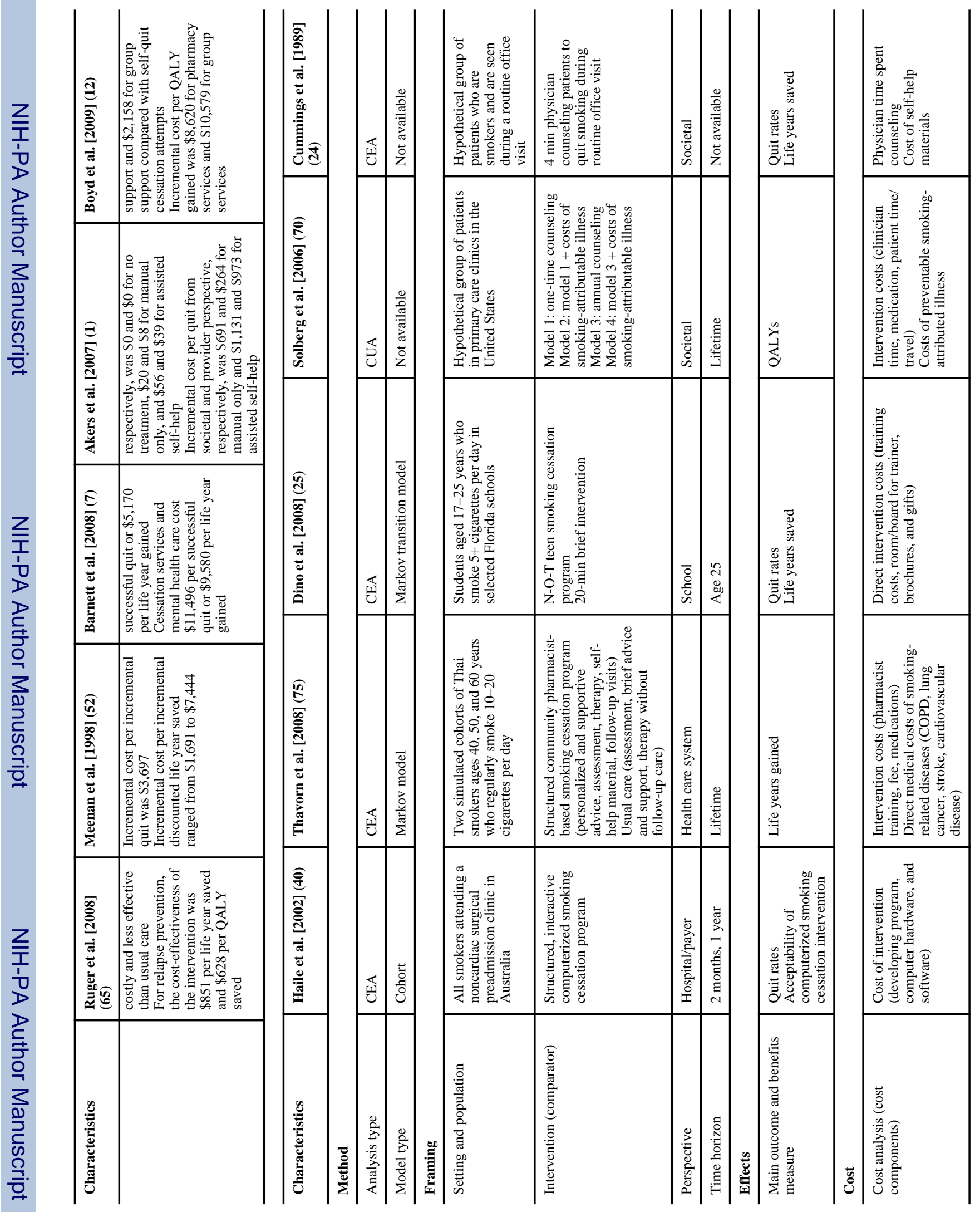

Annu Rev Public Health. Author manuscript; available in PMC 2014 March 19. 


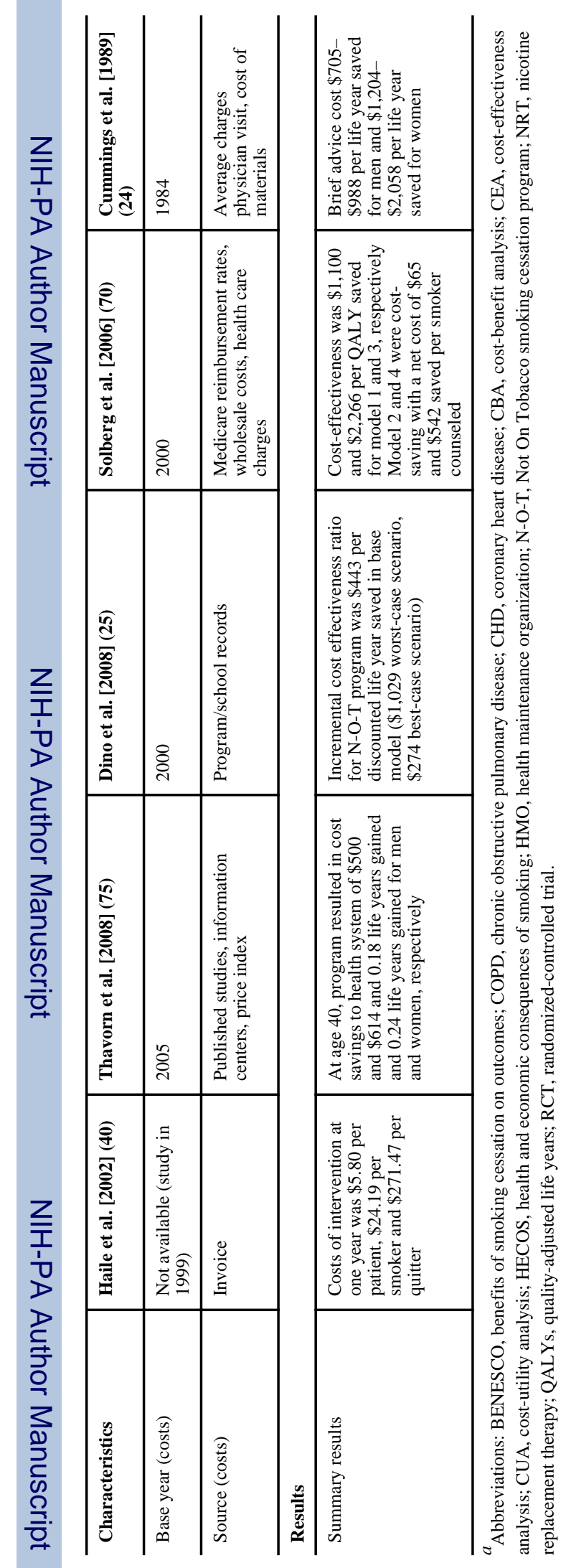

